OPEN ACCESS

Edited by:

Vito De Pinto,

University of Catania, Italy

Reviewed by:

Dario Mizrachi,

Brigham Young University,

United States

Fabrice Homblé,

Université libre de Bruxelles, Belgium

${ }^{*}$ Correspondence:

Girdhar K. Pandey

gkpandey@south.du.ac.in

Specialty section:

This article was submitted to Mitochondrial Research, a section of the journal

Frontiers in Physiology

Received: 22 March 2021

Accepted: 30 June 2021

Published: 05 August 2021

Citation:

Ravi B, Kanwar P, Sanyal SK, Bheri $M$ and Pandey GK (2021) VDACs: An Outlook on Biochemical Regulation and Function in Animal and Plant Systems.

Front. Physiol. 12:683920. doi: 10.3389/fphys.2021.683920

\section{VDACs: An Outlook on Biochemical Regulation and Function in Animal and Plant Systems}

\author{
Barkha Ravi, Poonam Kanwar, Sibaji K. Sanyal, Malathi Bheri and Girdhar K. Pandey* \\ Department of Plant Molecular Biology, University of Delhi, New Delhi, India
}

The voltage-dependent anion channels (VDACs) are the most abundant proteins present on the outer mitochondrial membrane. They serve a myriad of functions ranging from energy and metabolite exchange to highly debatable roles in apoptosis. Their role in molecular transport puts them on the center stage as communicators between cytoplasmic and mitochondrial signaling events. Beyond their general role as interchangeable pores, members of this family may exhibit specific functions. Even after nearly five decades of their discovery, their role in plant systems is still a new and rapidly emerging field. The information on biochemical regulation of VDACs is limited. Various interacting proteins and post-translational modifications (PTMs) modulate VDAC functions, amongst these, phosphorylation is quite noticeable. In this review, we have tried to give a glimpse of the recent advancements in the biochemical/interactional regulation of plant VDACs. We also cover a critical analysis on the importance of PTMs in the functional regulation of VDACs. Besides, the review also encompasses numerous studies which can identify VDACs as a connecting link between $\mathrm{Ca}^{2+}$ and reactive oxygen species signaling in special reference to the plant systems. Keywords: mitochondrial channel, biochemical regulation, phosphorylation, cell signaling, $\mathrm{Ca}^{2+}$, reactive oxygen
species, cellular homeostasis, CBL-CIPK

\section{INTRODUCTION}

Popularly known as the "powerhouse of the cell," mitochondria have risen from their classical biochemical functionality. The voltage-dependent anion channels (VDACs), first reported by Schein et al. (1976), are the most abundant, multi-functional family of pore-forming proteins present on the outer mitochondrial membrane (OMM; Benz, 1994; Colombini et al., 1996). The general structure of VDAC proteins can be described as a channel formed by $19 \beta$-barrels and an $\mathrm{N}$-terminal that folds in an $\alpha$-helix, horizontally within the pore (Bayrhuber et al., 2008; Hiller et al., 2008; Ujwal et al., 2008). The studies indicate that the permeability of the pore is majorly regulated by its voltage-dependent conformational state (open state shows slight preference for small anions while its closed state prefer cations) (Colombini, 1980; Benz et al., 1990; Hodge and Colombini, 1997), hence regulating organelle metabolism (Benz et al., 1988, 1990; Ludwig et al., 1988). The determination of VDACs as regulators of the OMM permeability, as well as in major molecular trafficking across the mitochondrial-cytoplasmic interface, revealed a new mitochondrial dimension on how they can regulate inputs according to external cues 
(Colombini, 1979). Additional discoveries depicted their crucial role in cell signaling, cytoplasmic-mitochondrial communication, aging, cell life, as well as the controversial cell death mechanism (Crompton, 1999; Griffiths, 2000; Colombini, 2004; Baines et al., 2007; Ott et al., 2007). VDACs have been reported from all the eukaryotes studied so far (De Pinto et al., 2003). Three of its isoforms are present in mammals, including humans (Menzel et al., 2009; Raschle et al., 2009; De Pinto et al., 2010), wherein hVDAC3 is accepted as the oldest isoform, and hVDAC1 is the recently evolved isoform (Young et al., 2007). However, their numbers are variable in plants and are generally more as compared to mammals. The Oryza sativa and Nicotiana tabacum have three VDAC isoforms (Al Bitar et al., 2003; Tateda et al., 2009), Arabidopsis thaliana has four VDAC isoforms (Clausen et al., 2004; Tateda et al., 2011), and Medicago trunculata, Lotus japonica, Phaseolus vulgaris, and Glycine max contain at least five putative VDACs (Clausen et al., 2004; Wandrey et al., 2004; Saidani et al., 2016). Their variable number in plants indicates that they might have a more diverse role in plants. While protein purification, sequence analysis, and/or structure prediction have already been reported from plants like wheat, rice, pea, pearl millet, maize, and potato (Aljamal et al., 1993; Fischer et al., 1994; Heinss et al., 1994; Elkeles et al., 1995; Geiger et al., 1999; Al Bitar et al., 2003), plant VDACs still require high-resolution structure revelation.

Voltage-dependent anion channel, being one of the major membrane protein in the OMM, can be modulated by factors like chemical compounds and other proteins or cellular metabolites. In this review, we provide an update on the biochemical regulation of VDACs and their impact on the physiological function of VDACs, with a particular emphasis on the plant system. Post-translational modifications (PTMs) are essential mechanisms that diversify protein functions (Lodish, 1981). Several PTMs on VDACs are reported in animal systems and predicted in plant systems (Elkeles et al., 1995; Al Bitar et al., 2003; Martel et al., 2014) and might be responsible for the multi-functionality of these proteins. Therefore, it becomes imperative that we look at their PTMs via phosphorylation and other modes of modification. Lastly, we will tackle the potential role of VDAC in being the focal point through which calcium $\left(\mathrm{Ca}^{2+}\right)$ and reactive oxygen species (ROS) signaling may crosstalk in the cell. This information should help us understand the functional significance of VDACs and explore the possibility that VDACs might have a role in inter-organellar communication for major cellular processes in plants.

\section{BIOCHEMICAL AND INTERACTIONAL REGULATIONS AFFECT VDAC FUNCTIONING IN PLANTS}

In the following sections, we discuss the various factors that influence the biochemical, structural, and functional aspects of VDACs.

\section{CHEMICAL COMPOUNDS: INTERACTIONAL INFLUENCES I}

Natural compounds or extracts from plants have served humankind from ancient times owing to their medicinal properties and diversity. The modulation of VDACs is reported by plant-based compounds (depicted in Figure 1), usually through binding. Curcumin, a pigmented polyphenolic compound extracted from Curcumin longa, is known for its anti-cancer properties (Aggarwal et al., 2003). Curcumin modulates hVDAC1 when reconstituted in a lipid bilayer (Tewari D. et al., 2015). Molecular docking and mutational analysis have shown that curcumin interacts with hVDAC1 through N-terminus (Lys 15, Arg 18, and Asp 19) at one end and the amino acid Tyr 198 located in the inner wall of the channel. Closure of hVDAC1 by curcumin might contribute to its known pro-apoptotic property (Tewari D. et al., 2015). An essential oil constituent, precocene II, inhibits the production of tricothecene in Fusarium graminearum, the causal agent of fusarium head blight (Yaguchi et al., 2009). This fungal component has been shown to bind the single VDAC in F. graminearum through the affinity magnetic bead method. The precocene II is responsible for the increased level of superoxide in mitochondria (Furukawa et al., 2015) postulated due to gate closing. However, its role in trichothecene production needs further validation (Maeda and Ohsato, 2017). Hydrogen peroxide $\left(\mathrm{H}_{2} \mathrm{O}_{2}\right)$ has been shown to modulate rat brain-VDAC1 through an electrophysiological approach. The conductance of VDAC was shown to increase upon $\mathrm{H}_{2} \mathrm{O}_{2}$ treatment, and its activity was restored by curcumin. The binding site of $\mathrm{H}_{2} \mathrm{O}_{2}$ on the channel identified through in silico molecular docking indicates a possibility of direct interaction between VDAC and $\mathrm{H}_{2} \mathrm{O}_{2}$ (Malik and Ghosh, 2020). Leaf extracts (aqueous-methanolic) from Centella asiatica (CA) quench ROS during ischemia-reperfusion injury by protecting $\mathrm{N} 2 \mathrm{a}$ cells due to antioxidant property. However, leaf extracts from CA failed to prevent IR injury in VDAC1 knocked down$\mathrm{N} 2 \mathrm{a}$ cells, which indicates the involvement of VDACs in the protective effect of CA. This was followed by reconstitution of hVDAC1 in the lipid bilayer membrane, CA treatment resulted in its increased single-channel conductance and stabilized the open state of hVDAC1 (Tewari et al., 2016). This might indicate the modulation of VDACs by CA, aiding its protective effects. A phyto-cannabinoid CBD (cannabidiol) derived from Cannabis spp. demonstrates antileukemic activity. They directly binds to hVDAC1 and resulted in decreased channel conductance depicted using western blotting, and single channel conductance in the planar lipid bilayer thereby causing CBD-induced cell death (Rimmerman et al., 2013). In-silico hVDAC1-CBD interaction analysis led to the identification of three putative residues at the N-terminus (Thr9, Asp12, and Leu13) and five neighboring pore residues (Val146, Gln157, Gly175, Gln182, and His184). Steric interaction and hydrogen bonds stabilized the binding, with Thr9, Asp12, and His184 contributing most highest in the binding (Olivas-Aguirre et al., 2019). In the follow up report, the effect of CBD and curcumin, along with six other phenolic compounds, was tested for their anticancer activity. 


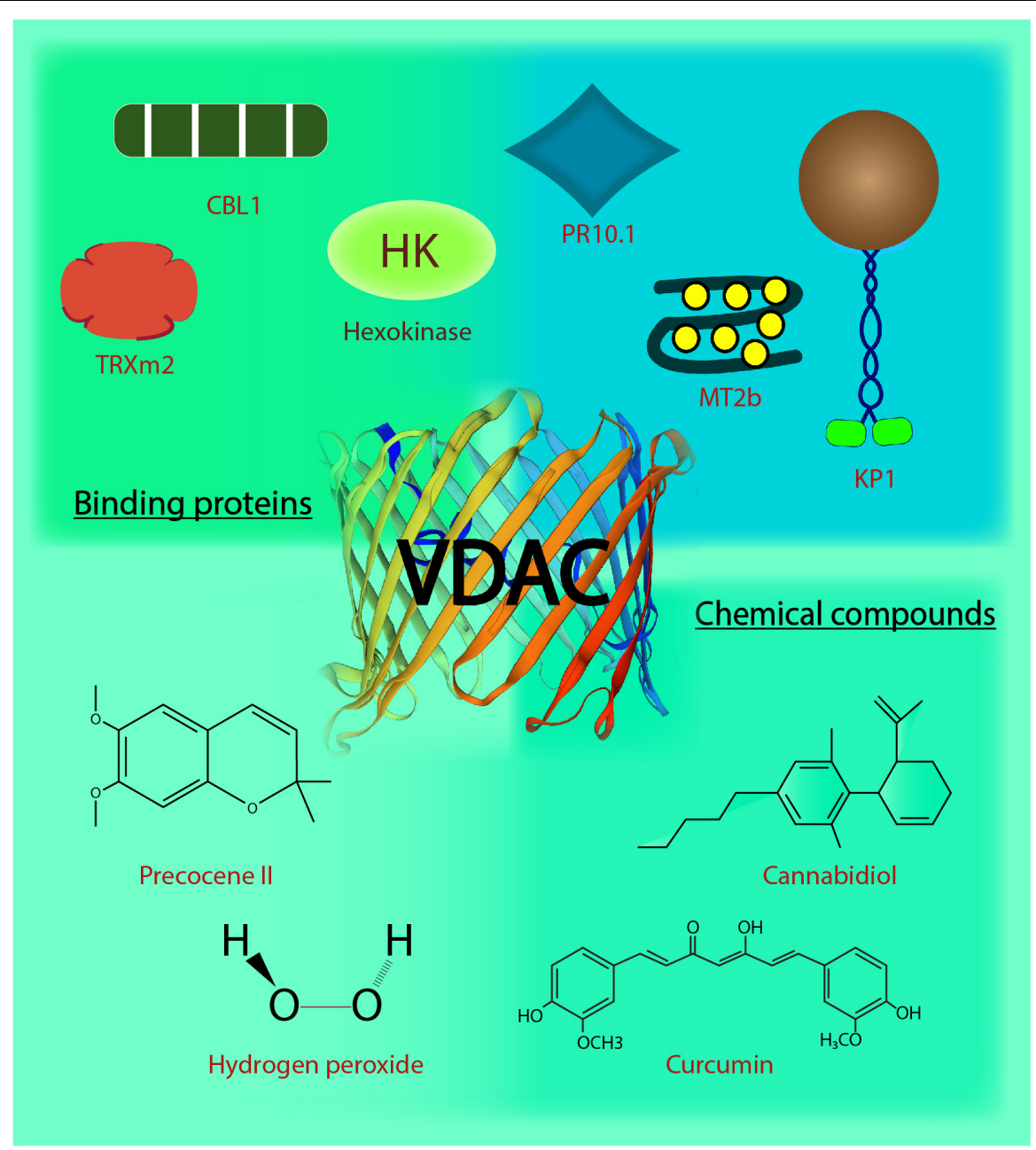

FIGURE 1 | Voltage-dependent anion channels in plants. The biochemical action and interaction of VDACs in plants affects their functional behavior. This image depicts the regulation and interaction of VDACs with binding proteins and chemical compounds. CBL1, Calcineurin B-like protein; TRXm2, chloroplast protein thioredoxin m2; MT2b, metallothionein $2 \mathrm{~b} ; \mathrm{H}_{2} \mathrm{O}_{2}$, hydrogen peroxide; $\mathrm{KP} 1$, plant kinesin protein 1; PR10.1, pathogenesis-related 10.1; $\mathrm{C}_{13} \mathrm{H}_{16} \mathrm{O}_{3}$, precocene II; $\mathrm{C}_{21} \mathrm{H}_{20} \mathrm{O}_{6}$, curcumin; $\mathrm{C}_{21} \mathrm{H}_{30} \mathrm{O}_{2}$, cannabidiol.

Out of these, CBD, curcumin and quercetin (another phenolic compound; Davis et al., 2009) preferred to interact on two specific residues (His184 and Thr9) predicted through in silico analysis and displayed cytotoxic effects in human T-ALL Jurket cell lines. $\mathrm{CBD}$ and curcumin were found to be the most conspicuous in causing cell death due to mitochondrial $\mathrm{Ca}^{2+}$ overload (OlivasAguirre et al., 2020). The regulation of human VDACs by plant extracts might indicate a new level of regulation operated by these plant-based metabolites, contributing to protective effects as witnessed in the case of apoptosis and cell death regulation. These plant-based natural compounds have potential to serve as anti-cancer drugs targeting mitochondria through VDACs. But, these prediction based on the above-mentioned studies lacks clinical potential viability and they need further exploration. Overall, the in vitro findings with reconstituted VDACs can help us infer better on the effect of plant extracts on VDACs and mitochondrial physiology in general. Moreover, their in vivo characterization will shed light on their degree of utilization. The identification of these candidate regulators from plants holds great therapeutic relevance.

\section{PROTEINS: INTERACTIONAL INFLUENCES II}

Voltage-dependent anion channel's interaction with many cytosolic proteins makes it a nexus for multiple cell signaling events. Interestingly, in plants, the reports on VDACs and their interacting partners (depicted in Figure 1) indicate that VDAC (and the particular partner) have a role in responding to abiotic and biotic stress, inter-organelle connection, metabolite flux at the cytosolic-mitochondrial interface, in addition to VDAC's probable role in programmed cell death. To begin with the role in stress signaling mechanism, a type 2 metallothioneins (MTs: small cysteine-rich, metal-binding proteins), have been shown to directly interact with AtVDAC3 in Arabidopsis 
through yeast two-hybrid $(\mathrm{Y} 2 \mathrm{H})$ and bimolecular fluorescence complementation (BiFC) assays. The AtMT2b overexpression plants exhibited increased salt tolerance, and AtMT2b may act as a negative regulator of AtVDAC3 (Zhang et al., 2019). Further, plant-specific calcineurin B-like proteins $(\mathrm{CBL})$ are one of the major $\mathrm{Ca}^{2+}$ sensors that integrate $\mathrm{Ca}^{2+}$ signaling to various abiotic stresses in plants (Pandey, 2008; Sanyal et al., 2015; Sanyal et al., 2016; Sanyal et al., 2020). AtVDAC1 in Arabidopsis physically interacts with AtCBL1 in vitro. Together, they regulate cold stress responses during plant development and seed germination (Li et al., 2013). This may also connect $\mathrm{Ca}^{2+}$ and ROS signaling pathways, extensively reviewed in the animal systems and discussed later in this review (Yan et al., 2006; Görlach et al., 2015; Feno et al., 2019). Recent discovery on mitochondrial regulation through interaction between chloroplast protein, thioredoxin $\mathrm{m} 2$ (AtTrx m2), and AtVDAC3, emphasizes an inter-organellar communication (Zhang et al., 2015). Y2H and pull-down assays have confirmed the physical interaction between the two, and BiFC assay has located the interaction on the mitochondria. This may act as another partner of VDAC3 for regulating ROS signaling and salt stress responses in plants (Zhang et al., 2015). VDAC3 from Vitis piasezkii Liuba8 was screened as an interacting partner of pathogenesis-related PR10.1 obtained from Vitis pseudoreticulata' Baihe-35-1 in $\mathrm{Y} 2 \mathrm{H}$ library screening. The interaction was further confirmed through immunoprecipitation assays; together they function in imparting cell death mediated defense response to downy mildew disease caused by Plasmopara viticola, a biotrophic parasite in grapevine (Ma et al., 2018). The finding substantiates the functional role of plant VDACs in pathogen defense (Lee et al., 2009; Tateda et al., 2009). Several animal kinesins such as those from mouse cells, KIF1B as well as KIF5B and Drosophila melanogaster, KLP67A kinesin are involved in the movement of mitochondria (Nangaku et al., 1994; Pereira et al., 1997; Tanaka et al., 1998). A plant-specific kinesin, KP1, is also found to interact with plant mitochondrial AtVDAC3 in Arabidopsis. AtKP1 interacts with AtVDAC3 via its tail domain and regulates respiration during seed germination at low temperatures in plants (Yang et al., 2011). This interaction between microtubule motor protein and mitochondrial channel indicates possibilities of involvement of plant kinesins in controlling the movement of mitochondria, which requires further investigation.

Mitochondria are the hub of aerobic oxidation in eukaryotic cells. The glycolytic enzymes associate dynamically with mitochondria and support respiration. Cytoskeletal protein tubulin can induce a reduced respiration rate by reversible blocking of VDAC, as observed through patch-clamp and planar lipid bilayer technique in animal and fungal systems (Rostovtseva et al., 2008). The involvement of VDACs in the regulation of respiration is reported in plants as well. Glycolytic enzymes, such as aldolases, interact strongly with AtVDAC protein and the latter may anchor the enzyme at the mitochondrial surface, thus facilitating substrate channeling (Graham et al., 2007). These findings are important in the study of the regulation of metabolic flux and involvement of VDACs in the plant metabolic networks. Additionally, the interaction of VDACs by glycolytic enzyme, hexokinases through in vitro and in vivo studies is a well-studied concept in animals (Abu-Hamad et al., 2008; Galluzzi et al., 2008; Pastorino and Hoek, 2008) and is projected as a strategy to aid conventional chemotherapeutics (Pastorino et al., 2002; Abu-Hamad et al., 2008). Mitochondrial hexokinase modulates the function of endogenous VDAC in tobacco bright yellow cell-2 (BY2 cells) as well as heterologous expressed OsVDAC4 in $N$. benthamiana leaves. Their co-expression limits their toxicity (independently overexpressing both the proteins causes toxicity in plants and cell death in BY2 cell lines), resulting in healthy cells and leaves in plants. The expression ratio of VDAC-hexokinase and their interactions are essential in cell death pathways in plants (Kim et al., 2006; Godbole et al., 2013). The heterologous expression indeed provides a clue on the importance of VDAChexokinase interaction; however, the functional validation of this entire pathway in the endogenous rice system itself can conclude better about its actual functionality.

\section{POST-TRANSLATIONAL MODIFICATIONS: REGULATION OF VDAC FUNCTION}

Reversible PTMs affect VDACs and their interaction with other proteins. VDACs are modulated post-translationally by phosphorylation, acetylation, GlcNAcylation, oxidative posttranslation modifications (Ox-PTMs), and ubiquitination. These modifications on VDACs will be discussed in the following sections.

\section{REGULATION THROUGH PHOSPHORYLATION}

Voltage-dependent anion channels undergo phosphorylation for modulation of their channel properties. To understand the biological significance of the phosphorylation event(s) in VDAC, it is necessary to identify the phosphorylation sites in VDACs, the protein mediating the phosphorylation, the physiological stimulus mediating the phosphorylation and the resultant change in VDAC (in particular) and physiology in general. In vitro and in silico analyses revealed many phosphorylation sites in isoforms of VDAC, which can play an important role in studying the function of VDAC in the near future. If we look into the studies performed till date to understand the phosphorylation events of VDAC, we can divide them into three main classes: (a) studies that proved VDAC can be phosphorylated which alters the channel properties, (b) studies where the whole proteome was examined to understand the PTM and (c) where the specific study on VDAC phosphorylation site was performed, followed by identification and validation.

The first group majorly consists of reports from the Ghosh laboratory (Bera et al., 1995; Bera and Ghosh, 2001; Banerjee and Ghosh, 2006; Gupta and Ghosh, 2017). They have used VDAC (not isoform-specific) from either rat liver (Bera et al., 1995; Bera and Ghosh, 2001) or rat brain (Banerjee and Ghosh, 2006; Gupta and Ghosh, 2017). This was followed by assessing the phosphorylation against protein kinase A (PKA) 
(Bera et al., 1995; Bera and Ghosh, 2001), the effect of Bax and tBid binding on VDAC (Banerjee and Ghosh, 2006) and PKA mediated phosphorylation and c-Jun N-terminal kinase3 (JNK3) (Gupta and Ghosh, 2017). They have identified PKA and JNK3 mediated phosphorylation of VDAC through in vitro kinase assays and followed it up with investigation of the changes in channel dynamics of VDAC due to phosphorylation in real time, using reconstitution in lipid membrane bilayer (Bera et al., 1995; Bera and Ghosh, 2001; Banerjee and Ghosh, 2006; Gupta and Ghosh, 2017). Their protocol, though, has given important insights into the phosphorylation of VDAC and the resultant change in the gating properties but lacks the information on the actual VDAC isoform being phosphorylated and also the phosphorylation site(s). Another similar study was reported by Baines and colleagues, where they analyzed the in vitro phosphorylation of mouse VDAC1 by protein kinase $\mathrm{C}$ (PKC). These studies gave some critical shreds of evidence on the PKC and VDAC interaction and probable regulation of mitochondrial permeability transition pore by $\mathrm{PKC}$, but in terms of phosphorylation, the information did not yield more knowledge beyond just the event.

The second group of studies provided an improvement from the first group by indicating the exact site of phosphorylation in VDAC (and also the particular isoform) under a certain stimulus (or a disease). Tyr phosphorylation of pig VDAC1 and VDAC2 were reported using immunoblotting followed by mass spectrometry (MS) under hypoxia, with no specific site identified (Liberatori et al., 2004). Using anti-Phospho-Tyr antibodies, Schwertz et al. (2007) showed that in rabbits, VDAC1 underwent Tyr phosphorylation during myocardial ischemia by p38 MAPK. Ballif et al. (2008) used MS on peptides extracted from mouse brain and identified Tyr phosphorylation on VDAC1 (Tyr80 and Tyr208), VDAC2 (Tyr207), and VDAC3 (Tyr49). Another study performed on HeLa cells stimulated by epidermal growth factor (EGF) identified phosphor-sites [(Ser101, Ser102, and Ser 104) and Thr 107] in VDAC1 and (Ser115 and Thr118) VDAC2 by MS (Olsen et al., 2006). All three isoforms of rat VDACs were phosphorylated at one or more sites, presumably without any treatment. The study identified Ser12 and Ser136 in VDAC1, Tyr237 in VDAC2, and Thr33 and Ser241 in VDAC3. These results were confirmed by MS (Distler et al., 2006, 2007). Two different groups reported Ser117 as a possible phosphorylation site in mouse VDAC1 using different tissues, again presumably without treatment (Lee et al., 2007; Munton et al., 2007). Tewari S. G. et al. (2015) have used a phospho-mimetic VDACSer137Glu in their studies and have shown that it affects the channel properties of rat VDAC1 (the probable isoform). A quick check of the rat VDAC1 sequence in the UniProt database (Q9Z2L0) indicates that the Ser is at position 137 (at 136 position there is a Pro). Therefore, we believe that it is the same Ser reported by Distler and colleagues (and also claimed by Tewari and colleagues). These studies were advancements on the first group as they yielded exact information on the VDAC isoforms and phosphorylation sites, and the last report indicates that there is merit in examining them more carefully.

Addressing the third and final group, that looks into the VDAC phosphorylation sites followed by validation of experimental results. There are three main candidates here: (1) the phosphorylation of VDAC by glycogen synthase kinase-3 (GSK-3), (2) the phosphorylation of VDAC during endostatin treatment, and (3) phosphorylation of VDAC by NIMA-related protein kinase 1 (Nek1). VDAC can be phosphorylated by Akt and GSK-3 (proved from rat heart, mouse liver and humans VDAC) (Pastorino et al., 2005; Das et al., 2008; Sheldon et al., 2011; Martel et al., 2014). Pastorino et al. (2005) used VDAC precipitated from HeLa cells (different stimulus applied to perturb GSK-3 expression) using a mouse anti-VDAC antibody and then assessed the phosphorylation status using an antiPhosphothreonine antibody. They further created a phosphormutant VDAC3Thr51Ala (from the consensus sequence for GSK-3 phosphorylation). An in vitro kinase assay showed that this particular variant was not phosphorylated by GSK-3 (Pastorino et al., 2005). By analyzing the mouse VDAC sequences provided in UniProt, we posit that the VDAC used in this study was either hVDAC1 (P21796) or hVDAC3 (Q9Y277) as they both have Thr at position 51. The phosphorylation of VDAC by GSK-3 at Thr residues were also validated in mice and human models by Martel et al. (2013) using both antibody (anti-Phosphothreonine) based approaches and in vitro kinase assay. This particular study used MS only to identify the VDAC isoform and not the phosphorylation site(s). But there are more Thr residues available (in humans, mice, and rats) that could be phosphorylated and need further validation. Nevertheless, Thr51 in human VDAC1 (or VDAC3) is a target of GSK-3 for modulating the channel properties. Yuan et al. (2008) showed that in endostatin-treated human cell line, VDAC1 could be immunoprecipitated by using a rabbit VDAC1 antibody, and its phosphorylation was detected on western blotting by probing with anti-Phosphoserine antibody. They created phosphormutant Ser12Ala and Ser103Ala, which showed reduced human VDAC1 accumulation after endostatin treatment, indicating that these sites are the probable phosphorylation sites. Hexokinase II, endostatin, PKC, and GSK-3 modulates VDAC function, however, it was hypothesized that either PKC or GSK-3 are the potential kinases regulating the phosphorylation of human VDAC1 in this case. Although there is no concrete proof of the identity of the kinases, this does question the earlier results, which had shown GSK-3 phosphorylating primarily Thr residues. Chen et al. $(2009,2010)$ reported that Nek1 interacts and phosphorylates human VDAC1 on Ser193 (by creating a phosphor mutant VDAC1Ser193Ala) residue using in vitro kinase assays. The Nek1 is regulated by TKL1 (Tousled-like kinase), which is also involved in chromatin assembly and DNA repair mechanism (Sunavala-Dossabhoy and De Benedetti, 2009). On investigating the entire TLK1-Nek1-VDAC1 module, VDAC1 was found to be a key link between mitochondria-mediated apoptosis and irreparable DNA damages (Singh et al., 2020).

We provide an interesting anecdote where it was shown that a kinase partner could modulate VDAC without phosphorylation. A Raf family Ser/Thr kinase, C-Raf, interacts and is targeted to $\mathrm{OMM}$ by $\mathrm{Bcl} 2$ protein in a kinase-substrate independent manner and is shown to suppress apoptosis in hemopoietic cell lines (Wang et al., 1994, 1996). However, a Bcl-2 independent mechanism controlled by C-Raf is also reported where C-Raf 
targeted to OMM forms a complex with human VDAC1 observed in co-immunoprecipitation studies. No phosphorylation was reported for this interaction (in both in vivo and in vitro experiments) (Le Mellay et al., 2002).

The phosphorylation sites detailed in the above paragraphs (and summarized in Table 1) put forward a fundamental question regarding the identity of the "phosphorylation switches" that can be utilized for future studies to modulate the VDAC for in vivo research. Although VDACs have similar sequences, there are abundant proofs that phosphorylation sites can differ based on species and kinase involved. We believe that the best approach to deal with this problem is -after the identification of a kinase partner of VDAC, an in vitro kinase assay is to be followed to first answer the question of phosphorylation-based regulation. This should be then followed by identification of sites by MS following either perturbing the organism with the stimulus that is being investigated or alternatively, by MS after an in vitro kinase assay. The results obtained from the MS analysis should be used to create either phospho-mimic or phosphor-mutant, and then one can proceed to analyze the channel conductance of these variants. These approaches should give us better results for the identification of actual site(s). Distressfully, the data on plant VDAC phosphorylation is still lacking.

\section{REGULATION THROUGH ALTERNATIVE ROUTES OF MODIFICATION}

Other than phosphorylation, regulation of VDACs necessitates comprehension of its alternative modes of PTM. Its regulation has also been observed via nitrosylation/nitrosation, acetylation, oxidation, and interaction with ubiquitin proteins. In vivo PTMs by nitrosylation of VDACs have not been directly reported, however, VDAC activity is known to be affected by Nitrous Oxide (NO) (Cheng et al., 2011). Moreover, in vitro nitrosation using PAPA NON-Oate (PPN) at $25 \mu \mathrm{M}$ showed that the conductance is reduced and the dwell time of rat VDAC is increased in the closed state. Also, at PPN100, the conductance was reported to be half of that is present in wild type (wt) (Tewari S. G. et al., 2015). The modification of VDACs induces significant changes in gating kinetics, which might affect mitochondrial (dys)function. The second type of PTM observed in VDACs is O-GlcNAcylation. $\mathrm{O}-\mathrm{GlcNAcylation}$ affects protein-protein interactions, activity, stability, and expression (Dias and Hart, 2007). VDACs show an increase in O-GlcNAcylation in rats that exhibit low running capacity. This modification might increase mitochondrial stability (Darley-Usmar et al., 2012; Johnsen et al., 2013). Interferon-induced protein with tetratricopeptide repeats 3 (IFIT3) is an interferon-stimulated through JAK/STAT signaling pathway during pancreatic ductal adenocarcinoma (PDAC) (Platanias, 2005; Neuzillet et al., 2015). It directly interacts and regulates VDAC2 through O-GlcNAcylation, which protects PDAC cells from chemotherapy-induced apoptosis (Wang Z. et al., 2020). The modification of VDACs by GlcNAcylation serves to increase mitochondrial stability. Protein modification through acetylation is also crucial in cellular function, though its biological significance is reported for limited substrates
(Polevoda et al., 1999; Perrier et al., 2005; Caesar et al., 2006). It either occurs co-translationally at N-terminal residues or posttranslationally on lysine (Lys) residue. Acetylation is reported at alanine, Ala 283 residue located at the N-terminal of VDAC1 from mature rat mitochondria, although its significance is not reported yet (Distler et al., 2007). However, they are suggested to function in protein-protein interaction, accumulation of mature protein in target organelles, and general protection of protein from degradation (Hershko et al., 1984; Manning and Manning, 2001; Pesaresi et al., 2003). Ox-PTMs, another type of PTMs reported in VDACs, is an emerging field, and it has broadened our understanding of redox regulation (Stipanuk et al., 2009; Ryan et al., 2014; Shakir et al., 2017). Cysteine (Cys) PTMs in VDAC isoforms have been recently determined using MS (Reina et al., 2020). There are two, nine, and six Cys residues in VDAC1, VDAC2, and VDAC3, respectively. Most of them are localized to facilitate their exposure to IMS (inter-membrane space). Detailed profiling of redox state of Cys and Met of rat VDAC3 has been reported. The evolutionary conservation of Cys modification in the three isoforms is observed in the rat and human VDACs (Saletti et al., 2017, 2018; Pittalà et al., 2020). A conserved oxidative status of Cys residues in rat and human VDAC1 is detected as trioxidized form (Cys127) and the reduced and carboxyamidomethylated form (Cys232) (Pittalà et al., 2020). However, in hVDAC1, there is no change in activity through the Ox-PTMs of the sulfhydryl groups. Cross-linking experiments deny the involvement of intermolecular S-S bridge leading to oligomerization (Aram et al., 2010; Teijido et al., 2012). In the case of VDAC2, the N-terminal Cys 8, 13, and 227 residues located on loop exposed to cytosol were reduced; Cys 47, 76, 103, and 210 residues, localized toward IMS were partially oxidized; and the Cys127 residue localized toward lipid environment was fully tri-oxidized (Pittalà et al., 2020). hVDAC3 contains six Cys2, $8,36,65,122$, and 229 residues. MS analyses showed that the Cys 2, 8, 122, and 229 residues were reduced, N-terminal Cys residue 2 was acetylated, residue 36 and 65 were reduced, and tri-oxidized to sulfonic acid (Saletti et al., 2018; Pittalà et al., 2020). Functional significance of the modifications in VDAC3 is reported for some of the residues. Electrophysiology and the ability to revert the growth phenotype of the yeast mutant, $\Delta$ por 1 , is strongly affected upon the deletion of Cys residues from engineered human VDAC3 (Okazaki et al., 2015; Reina et al., 2016). Cys 2, 8, and 122 residues seem to be more important for protein function; mutating them or a simultaneous mutation of any of these three Cys to Ala leads to restoration of large pores and the $\Delta$ por1 phenotype (Reina et al., 2016; Queralt-Martín et al., 2020). Cys modifications vary with isoforms as well as their position on VDAC channel. They could function in ROS signaling in mitochondria and this link needs to be explored further. We do not know the significance of the Cys residues in plants. The Arabidopsis VDACs have lesser (or none) Cys residues, and this may indicate an evolutionary change in the way plant VDACs function (Sanyal et al., 2020). Overexpression of VDAC3 is related to microglial I/R injury (Yao et al., 2018). VDACs exhibit temperature-sensitivity on activation and may contribute to hypothermic neuroprotection against oxygenglucose deprivation/recovery (OGD/R) (Imada et al., 2010). It 


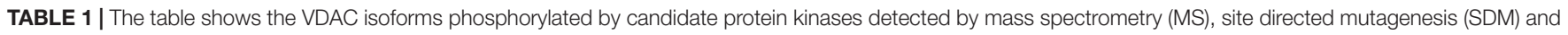
predicted sites with their functional consequences.

\begin{tabular}{|c|c|c|c|c|c|c|}
\hline Isoform & Regulation & Phosphorylation site & $\begin{array}{l}\text { Mode of site } \\
\text { detection }\end{array}$ & $\begin{array}{l}\text { Organism/organ } \\
\text { interaction found in }\end{array}$ & Protein kinase & Functional relevance \\
\hline VDAC1 & Phosphorylation & $S^{13}, S^{137}, S^{234}$ & $\begin{array}{l}\text { Predicted (Wang C. } \\
\text { et al., 2020) }\end{array}$ & Rat heart & $\mathrm{PKC} \varepsilon$ & $\begin{array}{l}\text { Cardio-protection } \\
\text { (Baines et al., 2003) }\end{array}$ \\
\hline VDAC1 & Interaction & $S^{12}, S^{103}$ & Experiment & $\begin{array}{l}\text { Human microvascular } \\
\text { endothelial cells }\end{array}$ & ES & $\begin{array}{l}\text { Endostatin-induced } \\
\text { endothelial cell } \\
\text { apoptosis (Yuan et al., } \\
\text { 2008) }\end{array}$ \\
\hline VDAC1 & Interaction & Not detected & None & Rat liver & C-Raf & $\begin{array}{l}\text { Apoptotic suppression } \\
\text { (Le Mellay et al., 2002) }\end{array}$ \\
\hline VDAC1 & Phosphorylation & $S^{45}$ & $\begin{array}{l}\text { Predicted (Wang C. } \\
\text { et al., 2020) }\end{array}$ & Rat liver & PKA & $\begin{array}{l}\text { Cytochrome mediated } \\
\text { cell death (Banerjee } \\
\text { and Ghosh, 2006) }\end{array}$ \\
\hline VDAC1 & Phosphorylation & $S^{193}$ & Experiment & Human cell lines & Nek1 & $\begin{array}{l}\text { Mitochondrial } \\
\text { Dysfunction and } \\
\text { apoptosis (Chen et al., } \\
\text { 2009) }\end{array}$ \\
\hline VDAC1 & Phosphorylation & $\begin{array}{l}S^{101 *}, S^{102 *}, S^{104 *} \\
T^{107 *}, S^{117}, T^{208}\end{array}$ & Experiment & $\begin{array}{l}\text { Rat liver, Human cell } \\
\text { lines }^{*}\end{array}$ & None & Not defined \\
\hline VDAC1 & Phosphorylation & $S^{136}$ & Experiment & Rat liver & PKC & Not defined \\
\hline VDAC1 & Phosphorylation & $S^{45}, S^{186}$ & $\begin{array}{l}\text { Predicted (Wang C. } \\
\text { et al., 2020) }\end{array}$ & Rabbit & p38 MAPK & $\begin{array}{l}\text { Ischemia/reperfusion } \\
\text { injury (Schwertz et al., } \\
\text { 2007) }\end{array}$ \\
\hline VDAC2 & Phosphorylation & $\mathrm{T}^{51}$ & Experiment & Rat heart & GSK3 & $\begin{array}{l}\text { Ischemia/reperfusion } \\
\text { injury (Pastorino et al., } \\
\text { 2005; Das et al., 2008) }\end{array}$ \\
\hline VDAC2 & Phosphorylation & $S^{115}, T^{118}$ & Experiment & Human cell lines & None & Not defined \\
\hline VDAC2 & Phosphorylation & $\mathrm{T}^{237}$ & Experiment & Rat liver & $\begin{array}{l}\text { INSR (Distler et al., } \\
\text { 2007) }\end{array}$ & Not defined \\
\hline VDAC2 & Phosphorylation & $T^{207}$ & Experiment & Rat brain & None & Not defined \\
\hline VDAC3 & Phosphorylation & $S^{241}$ & Experiment & Rat liver & None & Not defined \\
\hline VDAC3 & Phosphorylation & $\mathrm{T}^{33}$ & Experiment & Rat liver & None & Not defined \\
\hline VDAC3 & Phosphorylation & $S^{137}$ & Experiment & Rat liver & None & $\begin{array}{l}\text { Gating kinetics (Tewari } \\
\text { S. G. et al., 2015) }\end{array}$ \\
\hline VDAC3 & Phosphorylation & $\mathrm{T}^{49}$ & Experiment & Rat brain & None & Not defined \\
\hline VDAC & Phosphorylation & $T^{6}, S^{104}, S^{137}$ & $\begin{array}{l}\text { Predicted (Wang C. } \\
\text { et al., 2020) }\end{array}$ & Rat brain & JNK3 & Gating process \\
\hline VDAC1 & Phosphorylation & $\begin{array}{l}S^{44}, T^{45}, S^{103}, S^{233} \\
S^{264}\end{array}$ & $\begin{array}{l}\text { Predicted (Elkeles et al., } \\
\text { 1995) }\end{array}$ & $\begin{array}{l}\text { Wheat (Triticum } \\
\text { aestivum) }\end{array}$ & $\mathrm{PKC}$ & Not defined \\
\hline VDAC2 & Phosphorylation & $\begin{array}{l}S^{41}, T^{42}, T^{223}, S^{262} \\
S^{270}\end{array}$ & $\begin{array}{l}\text { Predicted (Elkeles et al., } \\
\text { 1995) }\end{array}$ & $\begin{array}{l}\text { Wheat (Triticum } \\
\text { aestivum) }\end{array}$ & $\mathrm{PKC}$ & Not defined \\
\hline VDAC3 & Phosphorylation & $\mathrm{T}^{44}, \mathrm{~S}^{102}, \mathrm{~S}^{225}, \mathrm{~S}^{264}$ & $\begin{array}{l}\text { Predicted (Elkeles et al., } \\
\text { 1995) }\end{array}$ & $\begin{array}{l}\text { Wheat (Triticum } \\
\text { aestivum) }\end{array}$ & PKC & Not defined \\
\hline VDAC1 & Phosphorylation & $\mathrm{T}^{81}, \mathrm{~T}^{156}, \mathrm{~S}^{206}$ & $\begin{array}{l}\text { Predicted (Elkeles et al., } \\
\text { 1995) }\end{array}$ & $\begin{array}{l}\text { Wheat (Triticum } \\
\text { aestivum) }\end{array}$ & Creatine kinase & Not defined \\
\hline VDAC2 & Phosphorylation & $\begin{array}{l}T^{78}, T^{164}, S^{204}, T^{214}, \\
T^{252}\end{array}$ & $\begin{array}{l}\text { Predicted (Elkeles et al., } \\
\text { 1995) }\end{array}$ & $\begin{array}{l}\text { Wheat (Triticum } \\
\text { aestivum) }\end{array}$ & Creatine kinase & Not defined \\
\hline VDAC3 & Phosphorylation & $S^{71}, T^{80}, T^{164}$ & $\begin{array}{l}\text { Predicted (Elkeles et al., } \\
\text { 1995) }\end{array}$ & $\begin{array}{l}\text { Wheat (Triticum } \\
\text { aestivum) }\end{array}$ & Creatine kinase & Not defined \\
\hline $\begin{array}{l}\text { VDAC1, } \\
\text { VDAC2, } \\
\text { VDAC3 }\end{array}$ & Phosphorylation & $\mathrm{T}^{51}, \mathrm{~S}^{109}, \mathrm{~S}^{269}$ & $\begin{array}{l}\text { Predicted (Al Bitar } \\
\text { et al., 2003) }\end{array}$ & Rice (Oryza sativa) & $\mathrm{PKC}$ & Not defined \\
\hline $\begin{array}{l}\text { VDAC1, } \\
\text { VDAC2, } \\
\text { VDAC3 }\end{array}$ & Phosphorylation & $\mathrm{T}^{87}, \mathrm{~T}^{170}, \mathrm{~S}^{209}$ & $\begin{array}{l}\text { Predicted (Al Bitar } \\
\text { et al., 2003) }\end{array}$ & Rice (Oryza sativa) & Casein Kinase II & Not defined \\
\hline
\end{tabular}

PKC, protein kinase C; ES, endostatin; C-Raf, Raf family Ser/Thr kinase; PKA, protein kinase A; Nek1, NIMA-related protein kinase 1; p38 MAPK, p38 MAP kinase; GSK3, glycogen synthase kinase; INSR, insulin receptor; JNK3, c-Jun N-terminal kinase-3. * Represents Human cell lines 
is facilitated by interaction between VDAC3 and ubiquitin. The extent of VDAC3 ubiquitination was found directly proportional to hypothermia duration, which may act as an endogenous protective pathway in hypothermia (Zhao et al., 2020). After many decades of research on VDACs, the molecular understanding of their PTM is still limited. The reports on the PTMs and regulation of VDACs are mostly limited to the identification of site and modes of regulation. Though several phosphorylation sites are present on VDACs, only a few are functionally characterized. More information on acetylation, GlcNAcylation, Ox-PTMs and ubiquitination is needed, particularly their functional characterization. Although phosphorylation has been studied more than other modifications, the mere identification of phosphorylation sites is not enough to relate to the functional attributes. Their biological significance needs to be examined critically to enable their implementation. Candidate interactors that regulate VDAC activity have immense therapeutic potential. In comparison, PTMs in the plant VDAC are still an emerging concept and need to be investigated substantially by the plant science community.

\section{VDACs CONNECT $\mathrm{Ca}^{2+}$ AND ROS SIGNALING}

$\mathrm{Ca}^{2+}$ is an important second messenger and plays a crucial role in signaling in all eukaryotes (Poovaiah et al., 1987; Clapham, 1995; Rudd and Franklin-Tong, 1999, 2001; Sanders et al., 1999; Trewavas, 1999; Harper, 2001; Pandey, 2008; Kudla et al., 2018; Tang et al., 2020). In a non-excitable cell, $\mathrm{Ca}^{2+}$ flux occurs between cytosol, plasma membrane (PM), and endoplasmic reticulum (ER). However, organelles such as mitochondria can also regulate $\mathrm{Ca}^{2+}$ signals (Patel and Muallem, 2011; Stael et al., 2012; Wagner et al., 2016; Costa et al., 2018). They are known to be critical regulators of cellular $\mathrm{Ca}^{2+}$ homeostasis. They can accumulate ions, including $\mathrm{Ca}^{2+}$ (up to several hundred times of initial $\mathrm{Ca}^{2+}$ concentration), from the suspended medium during electron transport (Rossi and Lehninger, 1963). The $\mathrm{Ca}^{2+}$ sequestration is an energy-dependent process (Gunter et al., 1994). Mitochondrial $\mathrm{Ca}^{2+}$ uptake and $\mathrm{Ca}^{2+}$ signals play a key role in cellular processes ranging from energy metabolism to cell death. Plant mitochondrial functions range beyond the passive storage/buffering of cytosolic $\mathrm{Ca}^{2+}$; they generate unique $\mathrm{Ca}^{2+}$ signatures in response to the external stimuli. Cytosolic and mitochondrial $\mathrm{Ca}^{2+}$ signatures are generated on the perception of stimuli, particularly under stress. Also, similar to cytosolic $\mathrm{Ca}^{2+}$ signatures, mitochondrial $\mathrm{Ca}^{2+}$ signatures are differentially sensitive to stimuli. Exposure to cold, touch, and osmotic stress results in very similar temporal kinetics of cytoplasmic free $\mathrm{Ca}^{2+}$ concentration, $\left[\mathrm{Ca}^{2+}\right]_{\mathrm{c}}$ and mitochondrial free $\mathrm{Ca}^{2+}$ concentration, $\left[\mathrm{Ca}^{2+}\right]_{m}$. This reflects its role in buffering the $\left[\mathrm{Ca}^{2+}\right]_{\mathrm{c}}$, with the stimuli such as oxidative stress and touch showing an independent $\mathrm{Ca}^{2+}$ regulation of mitochondria in addition to cytosolic signatures (Logan and Knight, 2003). $\mathrm{Ca}^{2+}$ concentration in the cytosol and mitochondria is regulated by utilizing $\mathrm{Ca}^{2+}$ transporters across the IMM. However, to facilitate $\mathrm{Ca}^{2+}$ flux across the organelle, it needs to bypass the OMM. This regulation requires certain $\mathrm{Ca}^{2+}$ transport/regulating system on OMM. The regulating mechanism/molecular components responsible for this flux of $\mathrm{Ca}^{2+}$ from mitochondria may help understand the process and utilize it further. VDAC located on OMM shows permeability to $\mathrm{Ca}^{2+}$, thus, acting as an important players in $\mathrm{Ca}^{2+}$ flux. VDAC is a candidate regulator that manages $\mathrm{Ca}^{2+}$ flow in and out of mitochondria (Wagner et al., 2016). It will be interesting to identify other regulatory components in such regulation and examine if it merges with cytosolic $\mathrm{Ca}^{2+}$ signaling for better stress adaptation in cells. However, the relationship between VDAC and $\mathrm{Ca}^{2+}$ is entrenched beyond their role in the $\mathrm{Ca}^{2+}$ movement. The role of VDACs regulating $\mathrm{Ca}^{2+}$ signaling in plants is beginning to emerge. Under unfavorable conditions, mitochondria connect and form a network with the rest of the cell to maintain cellular homeostasis (Zemirli et al., 2018). $\mathrm{Ca}^{2+}$ signaling is one of the modes of regulation. The physical interaction between AtVDAC1 and CBL1 is one such example, as described earlier. The expression profile of both AtVDAC1 and CBL1 indicates the role of this module in cold stress during seed germination (Li et al., 2013). Salt overly sensitive (SOS) pathway mediates $\mathrm{Ca}^{2+}$ based cellular signaling under salt stress (Ji et al., 2013). VDAC protein levels were elevated in response to short-term salinity exposure in maize roots (Zörb et al., 2010). Similarly, VDAC2 in plants may also be connected with $\mathrm{Ca}^{2+}$ signaling. AtVDAC2 might participate in stress response pathways, as the expression level of SOS genes changes with the expression level of VDAC2 in qRT-PCR studies (Wen et al., 2011, 2014; Liu et al., 2015). Though a direct involvement of VDACs is not reported in plants, however evidence does show their involvement in $\mathrm{Ca}^{2+}$ signaling. This indirect $\mathrm{Ca}^{2+}$ involvement may be an additional mode of stringent regulation in cellular signaling. Since research based on plant VDAC-Ca ${ }^{2+}$ regulation is bound to flourish in future, it is important to optimize protocols for quantification of $\mathrm{Ca}^{2+}$ levels. The technical difficulties in measuring mitochondrial $\mathrm{Ca}^{2+}$ levels have been overcome through the development of several in vivo $\mathrm{Ca}^{2+}$ monitoring methods. The developments in the measurement of mitochondrial $\mathrm{Ca}^{2+}$ levels have been covered in several studies (Pozzan and Rudolf, 2009; JeanQuartier et al., 2012; McKenzie et al., 2017; Fernandez-Sanz et al., 2019). Therefore, the in vivo dynamics of these $\mathrm{Ca}^{2+}$ signaling components and VDACs can shed more light on the real-time cellular $\mathrm{Ca}^{2+}$ status in unfavorable conditions.

VDAC mediated cyto-mitochondrial signaling as well as VDAC-mediated inter-organellar communication through $\mathrm{Ca}^{2+}$ in cellular metabolism and survival are vital to our understanding. Mitochondria can act as high capacity $\mathrm{Ca}^{2+}$ buffers that determine cytosolic $\left[\mathrm{Ca}^{2+}\right]$ transients through regulation of the kinetic characteristics of $\mathrm{Ca}^{2+}$ channels or prevention of $\mathrm{Ca}^{2+}$ diffusion from the location of open channels. They may be critically involved in constraining $\mathrm{Ca}^{2+}$ signals in spatial terms to specific cellular domains (Rizzuto et al., 2012). The presence of $\mathrm{Ca}^{2+}$ hot spots on the mitochondrial surface in the regions closely apposed to $\mathrm{Ca}^{2+}$ channels localized on the PM or ER, contribute to the fast and high levels of $\mathrm{Ca}^{2+}$ uptake by mitochondria as observed in live cells (De Stefani et al., 2016). The proximity between the mitochondrial and 
ER membranes favors $\mathrm{Ca}^{2+}$ exchanges between them. Their entwined endomembrane network may regulate intracellular $\mathrm{Ca}^{2+}$ signaling via VDACs. The transmission of $\mathrm{Ca}^{2+}$ signals between the two was imaged through $\mathrm{Ca}^{2+}$ sensitive GFPs and aequorin probes. The $\mathrm{Ca}^{2+}$ release from ER was coordinated with $\mathrm{Ca}^{2+}$ uptake from mitochondria via VDAC (Rapizzi et al., 2002). The coupling of the two organelles can be chaperonemediated, which directly enhances the accumulation of $\mathrm{Ca}^{2+}$ in mitochondria. Glucose regulated protein 75, a cytosolic chaperone homologous to HSP70, physically connects VDAC1 (on OMM) to Inositol 1,4,5-triphosphate receptor ( $\mathrm{IP}_{3} \mathrm{R}$ : on $\mathrm{ER}$ ) and is a determining factor for the interaction as its absence abolished the stimulatory effect. This direct enhancement of $\mathrm{Ca}^{2+}$ accumulation in mitochondria forms a molecular bridge (Szabadkai et al., 2006). Co-immunoprecipitation assays further indicate the complex formation of $\mathrm{IP}_{3}$ receptor and VDAC1, regulated by apoptotic stimuli. VDAC1 silencing impaired the transfer of apoptotic $\mathrm{Ca}^{2+}$ signals selectively (De Stefani et al., 2012). Together, these reports demonstrate the regulation of inter-organellar communication through $\mathrm{Ca}^{2+}$ signaling, and VDACs constitute a significant part of this machinery. $\mathrm{Ca}^{2+}$ mediated inter-organellar connections in plants are beginning to emerge. This has been discussed in several reviews (Stael et al.,
2012; Kmiecik et al., 2016; Himschoot et al., 2017; Costa et al., 2018; Liu and Li, 2019; Navazio et al., 2020).

Antioxidant systems in mitochondria regulate the maintenance of ROS at physiological levels through mitochondrial metabolism. ROS imbalances in mitochondria, either through overproduction or impaired antioxidant system, lead to mitochondrial dysfunction and induction of the apoptotic cascade. Such ROS imbalances in pathological conditions exhibit a $\mathrm{Ca}^{2+}$ overload in mitochondria (Feno et al., 2019). Since mitochondrial ROS can act as a signaling molecule and not just be a by-product of oxidation reaction during ATP production, it is interesting to look at its signaling aspect (Collins et al., 2012; Sena and Chandel, 2012; Sullivan and Chandel, 2014). Mitochondrial $\mathrm{Ca}^{2+}$ uptake impinges on enzymes of the TCA cycle and the activity of the electron transport chain (ETC), generating ROS signals under physiological conditions depending on tissue specificity. This signaling aspect depends on $\left[\mathrm{Ca}^{2+}\right]$ threshold, which, when overcome, results in detrimental mROS levels, compromising mitochondrial bioenergetics and cellular functioning (Brookes et al., 2004; Görlach et al., 2015; Feno et al., 2019). The reciprocal interactions between the major signaling components, $\mathrm{Ca}^{2+}$ and ROS, regulating each other, form a "feed-forward, self-amplified loop." The resultant

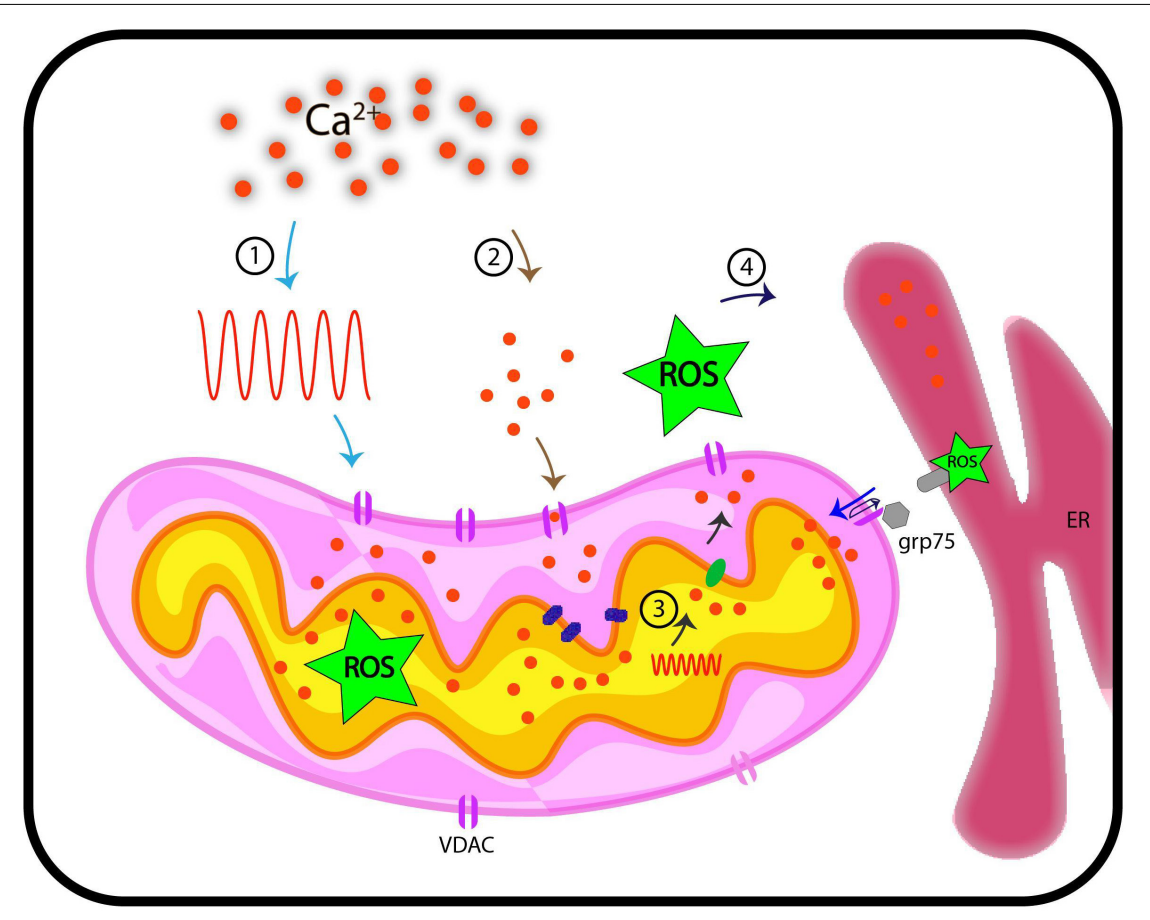

FIGURE 2 | Representation of functional implications of VDACs, $\mathrm{Ca}^{2+}$, and ROS in cellular signaling. This hypothetical model traces pathways through which VDAC may regulate $\mathrm{Ca}^{2+}$ and $\mathrm{ROS}$ signaling in plants. We discuss here four possible routes that we currently posit are VDAC mediated connection between $\mathrm{Ca}^{2+}$ and ROS signaling. (1) When cytosolic $\mathrm{Ca}^{2+}$ level increases on perception of stimuli (generation of $\mathrm{Ca}^{2+}$ signature), these signals are transduced downstream, where they influence the activity of VDACs. This might results in increased level of ROS in mitochondria. (2) VDAC serves passively to regulate $\mathrm{Ca}^{2+}$ levels in mitochondria. (3) Stimuli such as oxidative stress (inclusive of increased ROS level) and touch response results in generation of $\mathrm{Ca}^{2+}$ signature in mitochondria, independent of cytosolic $\mathrm{Ca}^{2+}$ signature. (4) VDAC can be a candidate protein that leads to flux of $\mathrm{Ca}^{2+} / \mathrm{ROS}$ from inter-membrane space to cytosol. Further, VDACs are known to connect ER based $\mathrm{Ca}^{2+}$ signaling and mitochondria through $\mathrm{Ca}^{2+}$ and ROS molecules and this may depict another possible mechanism of how VDAC connects $\mathrm{Ca}^{2+}$ and ROS. These hypothetical routes may (or may not) be connected. ER, endoplasmic reticulum; ROS, reactive oxygen species; grp75, glucose related protein 75 ; $\mathrm{Ca}^{2+}$, calcium; VDAC, voltage-dependent anion channel. 
oxidative damage can be more than that is directly caused by $\mathrm{Ca}^{2+}$ overload (Jou, 2008; Smaili et al., 2009; Peng and Jou, 2010). VDAC may serve as a junction for the interconnection of the two signaling molecules, ROS and $\mathrm{Ca}^{2+}$. The molecular link between $\mathrm{Ca}^{2+}$ and ROS through VDAC is evident, as already discussed. VDAC1 is linked to redox-sensitive ER $\mathrm{Ca}^{2+}$-release channel, $\mathrm{IP}_{3} \mathrm{R}$ by GRP-75 chaperone (Szabadkai et al., 2006), indicating that ROS and ER based $\mathrm{Ca}^{2+}$ signaling pathways are inter-linked. This inter-connection through VDAC is reported in yeast as well. ATP synthase along with the porin complex regulates $\mathrm{Ca}^{2+}$ homeostasis and permeability transition of mitochondria in vivo (Niedzwiecka et al., 2018). In lung cancer cells, a member of the Bcl-2 family, $\mathrm{Mcl}$ binds with VDAC1 and VDAC2. Disruption in this interaction limits $\mathrm{Ca}^{2+}$ uptake, which further inhibits ROS generation and shows VDACbased $\mathrm{Ca}^{2+}$ dependent ROS production (Huang et al., 2014). The generation of oxidative damage in cardiac microvascular endothelial cell injury (CMEC injury) is based on $\mathrm{IP}_{3} \mathrm{R}-\mathrm{VDAC}$ $\mathrm{Ca}^{2+}$. Simulation of MAPK/ERK by melatonin inactivates cAMP response element-binding protein (CREB), thus, blocking oxidative stress damage responsible for cardiac dysfunction (Zhu et al., 2018). The closure of VDAC by phosphorothioate increased superoxide in mitochondria because its flux from the inner mitochondrial space to the cytosol is affected. This results in $\mathrm{Ca}^{2+}$-induced mitochondrial permeability transition, causing the induced opening of permeability transition pores of high conductance in IMM due to excessive $\mathrm{Ca}^{2+}$ uptake (Tikunov et al., 2010). The notable roles of animal VDACs make the effort to pursue plant VDACs for their involvement in stress responses worthy. The research so far is pioneering in showing VDAC as a linking bridge between $\mathrm{ROS}$ and $\mathrm{Ca}^{2+}$ but we still lag in understanding the initiation of this loop. It is still emerging if mitochondrial $\mathrm{Ca}^{2+}$ signal generates a ROS signaling event or flux of ROS via mitochondrial stimulation of $\mathrm{Ca}^{2+}$ signaling in cytosol/mitochondria. It is still unclear whether the process is only facilitated by VDACs majorly and independently or does it need a complex to regulate the signaling. We expect studies in the future to depict the cytosolic and mitochondrial $\mathrm{Ca}^{2+}$ dynamics in the absence of VDAC in plants that can clarify the involvement of VDAC in the process. The simultaneous imaging of ROS and $\mathrm{Ca}^{2+}$ in reference to VDACs and their patterns in real-time also demand attention. Nevertheless, at present, it is an open question that needs to be investigated in plants. We also expect research in the future that can solve the mode of regulation in VDACs in these signaling events. It is a challenging opportunity to elucidate the entire signaling mechanism, including $\mathrm{Ca}^{2+}$-ROS homeostasis, in the context of cell biology. The interconnection between pathways and the role of VDACs as the central node as shown in Figure $\mathbf{2}$ is highly important and needs to be pursued further.

\section{REFERENCES}

Abu-Hamad, S., Zaid, H., Israelson, A., Nahon, E., and Shoshan-Barmatz, V. (2008). Hexokinase-I protection against apoptotic cell death is mediated via

\section{CONCLUSION AND FUTURE PERSPECTIVE}

Significant knowledge on VDAC has accumulated in recent years. The functional range of VDACs as gating proteins has now expanded. We know the localization of VDACs, their modulation, biochemical regulation and functional implications in animals and, to some extent, in plants. Multi-localization of VDAC on different membranes, yet the difference in their functions, is an example of how nature increases diversity with existing tools in the cell. The multi-localization of VDAC can be predicted as a connecting route for better intra-cellular communication. However, its localization on PM is highly debatable. Different modes of regulation of VDACs make them versatile and hence, explains their ability to regulate and participate in multiple signaling events. The research on biochemical regulation is still limited and extensive intervention is the need of the hour. These channels are well known for molecular transport, and this function also puts them under the spotlight as communicators between cytoplasmic and mitochondrial signaling events. A mutual interplay between $\mathrm{Ca}^{2+}$ and ROS is also mediated by VDACs, and hence, they can be a $\mathrm{Ca}^{2+}$-ROS connecting link. However, many interesting questions remain to be addressed. At present, the ongoing research on plant VDACs faces many challenges, with burning questions and controversies. Its structure, isoforms in plants, role in apoptosis, relation with PCD and the VDAC interactome are gray areas. The active components extracted from plants can modulate animal VDACs. Their functional significance on plant VDACs will be a great help to further our understanding. Fortunately, the once lagging plant VDACs have emerged as a new arena of research. Based on the studies so far, VDACs have immense potential in therapeutics and the improvement of crops. The ongoing research will further unmask its functional significance, particularly, in plants.

\section{AUTHOR CONTRIBUTIONS}

GP conceptualized the review. BR and GP wrote the manuscript. $\mathrm{BR}, \mathrm{PK}, \mathrm{SS}, \mathrm{MB}$, and GP reviewed and revised the manuscript. All authors contributed to the article and approved the submitted version.

\section{FUNDING}

We are thankful to Delhi University (IoE/FRP grant), Department of Biotechnology (DBT), Science and Engineering Research Board (SERB), Council of Scientific and Industrial Research (CSIR), India for research funding in our lab. BR acknowledges CSIR for CSIR-SRF.

interaction with the voltage-dependent anion channel-1: mapping the site of binding. J. Biol. Chem. 283, 13482-13490. doi: 10.1074/jbc.m708216200

Aggarwal, B. B., Kumar, A., and Bharti, A. C. (2003). Anticancer potential of curcumin: preclinical and clinical studies. Anticancer Res. 23, 363-398. 
Al Bitar, F., Roosens, N., Smeyers, M., Vauterin, M., Van Boxtel, J., Jacobs, M., et al. (2003). Sequence analysis, transcriptional and posttranscriptional regulation of the rice vdac family. Biochim. Biophys. Acta Gene Struct. Expr. 1625, 43-51. doi: 10.1016/s0167-4781(02)00590-0

Aljamal, J. A., Genchi, G., De Pinto, V., Stefanizzi, L., De Santis, A., Benz, R., et al. (1993). Purification and characterization of porin from corn (Zea mays L.) mitochondria. Plant Physiol. 102, 615-621. doi: 10.1104/pp.102.2.615

Aram, L., Geula, S., Arbel, N., and Shoshan-Barmatz, V. (2010). VDAC1 cysteine residues: topology and function in channel activity and apoptosis. Biochem. J. 427, 445-454. doi: 10.1042/bj20091690

Baines, C. P., Kaiser, R. A., Sheiko, T., Craigen, W. J., and Molkentin, J. D. (2007). Voltage-dependent anion channels are dispensable for mitochondrialdependent cell death. Nat. Cell Biol. 9, 550-555. doi: 10.1038/ncb1575

Baines, C. P., Song, C. X., Zheng, Y. T., Wang, G. W., Zhang, J., Wang, O. L., et al. (2003). Protein kinase $C \varepsilon$ interacts with and inhibits the permeability transition pore in cardiac mitochondria. Circ. Res. 92, 873-880. doi: 10.1161/ 01.res.0000069215.36389.8d

Ballif, B. A., Carey, G. R., Sunyaev, S. R., and Gygi, S. P. (2008). Large-scale identification and evolution indexing of tyrosine phosphorylation sites from murine brain. J. Proteome Res. 7, 311-318. doi: 10.1021/pr0701254

Banerjee, J., and Ghosh, S. (2006). Phosphorylation of rat brain mitochondrial voltage-dependent anion as a potential tool to control leakage of cytochrome c. J. Neurochem. 98, 670-676. doi: 10.1111/j.1471-4159.2006.03853.x

Bayrhuber, M., Meins, T., Habeck, M., Becker, S., Giller, K., Villinger, S., et al. (2008). Structure of the human voltage-dependent anion channel. Proc. Natl. Acad. Sci. U.S.A. 105, 15370-15375.

Benz, R. (1994). Permeation of hydrophilic solutes through mitochondrial outer membranes: review on mitochondrial porins. BBA Rev. Biomembr. 1197, 167196. doi: 10.1016/0304-4157(94)90004-3

Benz, R., Kottke, M., and Brdiczka, D. (1990). The cationically selective state of the mitochondrial outer membrane pore: a study with intact mitochondria and reconstituted mitochondrial porin. BBA Biomembr. 1022, 311-318. doi: 10.1016/0005-2736(90)90279-w

Benz, R., Wojtczak, L., Bosch, W., and Brdiczka, D. (1988). Inhibition of adenine nucleotide transport through the mitochondrial porin by a synthetic polyanion. FEBS Lett. 231, 75-80. doi: 10.1016/0014-5793(88)80706-3

Bera, A. K., and Ghosh, S. (2001). Dual mode of gating of voltage-dependent anion channel as revealed by phosphorylation. J. Struct. Biol. 135, 67-72. doi: 10.1006/jsbi.2001.4399

Bera, A. K., Ghosh, S., Das, S., and Das, S. (1995). Mitochondrial VDAC Can Be Phosphorylated by Cyclic AMP-Dependent Protein Kinase. Biochem. Biophys. Res. Commun. 209, 213-217. doi: 10.1006/bbrc.1995.1491

Brookes, P. S., Yoon, Y., Robotham, J. L., Anders, M. W., and Sheu, S. S. (2004). Calcium, ATP, and ROS: a mitochondrial love-hate triangle. Am. J. Physiol. Cell Physiol. 287, C817-C833.

Caesar, R., Warringer, J., and Blomberg, A. (2006). Physiological importance and identification of novel targets for the N-terminal acetyltransferase NatB. Eukaryot. Cell 5, 368-378. doi: 10.1128/ec.5.2.368-378.2006

Chen, Y., Craigen, W. J., and Riley, D. J. (2009). Cell Cycle Nek1 regulates cell death and mitochondrial membrane permeability through phosphorylation of VDAC1. Cell Cycle 8, 257-267. doi: 10.4161/cc.8.2.7551

Chen, Y., Gaczynska, M., Osmulski, P., Polci, R., and Riley, D. J. (2010). Phosphorylation by Nek1 regulates opening and closing of voltage dependent anion channel 1. Biochem. Biophys. Res. Commun. 394, 798-803. doi: 10.1016/ j.bbrc.2010.03.077

Cheng, Q., Sedlic, F., Pravdic, D., Bosnjak, Z. J., and Kwok, W.-M. (2011). Biphasic effect of nitric oxide on the cardiac voltage-dependent anion channel. FEBS Lett. 585, 328-334. doi: 10.1016/j.febslet.2010.12.008

Clapham, D. E. (1995). Calcium signaling. Cell 80, 259-268.

Clausen, C., Ilkavets, I., Thomson, R., Philippar, K., Vojta, A., Möhlmann, T., et al. (2004). Intracellular localization of VDAC proteins in plants. Planta 220, 30-37. doi: 10.1007/s00425-004-1325-3

Collins, Y., Chouchani, E. T., James, A. M., Menger, K. E., Cochemé, H. M., and Murphy, M. P. (2012). Mitochondrial redox signalling at a glance. J. Cell Sci. 125, 801-806. doi: 10.1242/jcs.098475

Colombini, M. (1979). A candidate for the permeability pathway of the outer mitochondrial membrane [19]. Nature 279, 643-645. doi: 10.1038/279643a0
Colombini, M. (1980). Structure and mode of action of a voltage dependent anionchannel (VDAC) located in the outer mitochondrial membrane. Ann. N. Y. Acad. Sci. 341, 552-563. doi: 10.1111/j.1749-6632.1980.tb47198.x

Colombini, M. (2004). VDAC: the channel at the interface between mitochondria and the cytosol. Mol. Cell. Biochem. 256/257, 107-115. doi: 10.1023/b:mcbi. $0000009862.17396 .8 \mathrm{~d}$

Colombini, M., Blachly-Dyson, E., and Forte, M. (1996). VDAC, a channel in the outer mitochondrial membrane. Ion Channels 4, 169-202. doi: 10.1007/978-14899-1775-1_5

Costa, A., Navazio, L., and Szabo, I. (2018). The contribution of organelles to plant intracellular calcium signalling. J. Exp. Bot. 69, 4175-4193. doi: 10.1093/jxb/ ery185

Crompton, M. (1999). The mitochondrial permeability transition pore and its role in cell death. Biochem. J. 341, 233-249. doi: 10.1042/bj3410233

Darley-Usmar, V. M., Ball, L. E., and Chatham, J. C. (2012). Protein O-linked $\beta-N-$ acetylglucosamine: a novel effector of cardiomyocyte metabolism and function. J. Mol. Cell. Cardiol. 52, 538-549. doi: 10.1016/j.yjmcc.2011.08.009

Das, S., Wong, R., Rajapakse, N., Murphy, E., and Steenbergen, C. (2008). Glycogen synthase kinase 3 inhibition slows mitochondrial adenine nucleotide transport and regulates voltage-dependent anion channel phosphorylation. Circ. Res. 103, 983-991. doi: 10.1161/circresaha.108.178970

Davis, J. M., Murphy, E. A., and Carmichael, M. D. (2009). Effects of the dietary flavonoid quercetin upon performance and health. Curr. Sports Med. Rep. 8, 206-213. doi: 10.1249/jsr.0b013e3181ae8959

De Pinto, V., Guarino, F., Guarnera, A., Messina, A., Reina, S., Tomasello, F. M., et al. (2010). Characterization of human VDAC isoforms: A peculiar function for VDAC3? Biochim. Biophys. Acta Bioenerg. 1797, 1268-1275. doi: 10.1016/j. bbabio.2010.01.031

De Pinto, V., Messina, A., Accardi, R., Aiello, R., Guarino, F., Tomasello, M. F., et al. (2003). New functions of an old protein: the eukaryotic porin or voltage dependent anion selective channel (VDAC). Ital. J. Biochem. 52, $17-24$.

De Stefani, D., Bononi, A., Romagnoli, A., Messina, A., De Pinto, V., Pinton, P., et al. (2012). VDAC1 selectively transfers apoptotic Ca 2 signals to mitochondria. Cell Death Differ. 19, 267-273. doi: 10.1038/cdd.2011.92

De Stefani, D., Rizzuto, R., and Pozzan, T. (2016). Enjoy the trip: calcium in mitochondria back and forth. Annu. Rev. Biochem. 85, 161-192. doi: 10.1146/ annurev-biochem-060614-034216

Dias, W. B., and Hart, G. W. (2007). O-GlcNAc modification in diabetes and Alzheimer's disease. Mol. Biosyst. 3, 766-772. doi: 10.1039/b704905f

Distler, A. M., Kerner, J., and Hoppel, C. L. (2007). Post-translational modifications of rat liver mitochondrial outer membrane proteins identified by mass spectrometry. Biochim. Biophys. Acta Proteins Proteomics 1774, 628-636. doi: 10.1016/j.bbapap.2007.03.012

Distler, A. M., Kerner, J., Peterman, S. M., and Hoppel, C. L. (2006). A targeted proteomic approach for the analysis of rat liver mitochondrial outer membrane proteins with extensive sequence coverage. Anal. Biochem. 356, 18-29. doi: 10.1016/j.ab.2006.03.053

Elkeles, A., Devos, K. M., Graur, D., Zizi, M., and Breiman, A. (1995). Multiple cDNAs of wheat voltage-dependent anion channels (VDAC): isolation, differential expression, mapping and evolution. Plant Mol. Biol. 29, 109-124. doi: 10.1007/bf00019123

Feno, S., Butera, G., Reane, D. V., Rizzuto, R., and Raffaello, A. (2019). Crosstalk between calcium and ROS in pathophysiological conditions. Oxid. Med. Cell. Longev. 2019:9324018.

Fernandez-Sanz, C., De la Fuente, S., and Sheu, S. S. (2019). Mitochondrial Ca2+ concentrations in live cells: quantification methods and discrepancies. FEBS Lett. 593, 1528-1541. doi: 10.1002/1873-3468.13427

Fischer, K., Weber, A., Brink, S., Arbinger, B., Schünemann, D., Borchert, S., et al. (1994). Porins from plants: Molecular cloning and functional characterization of two new members of the porin family. J. Biol. Chem. 269, 25754-25760. doi: 10.1016/s0021-9258(18)47312-7

Furukawa, T., Sakamoto, N., Suzuki, M., Kimura, M., Nagasawa, H., and Sakuda, S. (2015). Precocene II, a trichothecene production inhibitor, binds to voltagedependent anion channel and increases the superoxide level in mitochondria of Fusarium graminearum. PLoS One 10:e0135031. doi: 10.1371/journal.pone. 0135031 
Galluzzi, L., Kepp, O., Tajeddine, N., and Kroemer, G. (2008). Disruption of the hexokinase-VDAC complex for tumor therapy. Oncogene 27, 4633-4635. doi: 10.1038/onc.2008.114

Godbole, A., Dubey, A. K., Reddy, P. S., Udayakumar, M., and Mathew, M. K. (2013). Mitochondrial VDAC and hexokinase together modulate plant programmed cell death. Protoplasma 250, 875-884. doi: 10.1007/s00709-0120470-y

Görlach, A., Bertram, K., Hudecova, S., and Krizanova, O. (2015). Calcium and ROS: a mutual interplay. Redox Biol. 6, 260-271. doi: 10.1016/j.redox.2015.08. 010

Graham, J. W. A., Williams, T. C. R., Morgan, M., Fernie, A. R., Ratcliffe, R. G., and Sweetlove, L. J. (2007). Glycolytic enzymes associate dynamically with mitochondria in response to respiratory demand and support substrate channeling. Plant Cell 19, 3723-3738. doi: 10.1105/tpc.107.053371

Griffiths, E. (2000). Mitochondria - potential role in cell life and death. Cardiovasc. Res. 46, 24-27. doi: 10.1016/s0008-6363(00)00020-1

Gunter, T. E., Gunter, K. K., Sheu, S. S., and Gavin, C. E. (1994). Mitochondrial calcium transport: Physiological and pathological relevance. Am. J. Physiol. Cell Physiol. 267(2 Pt 1), C313-C339.

Gupta, R., and Ghosh, S. (2017). Phosphorylation of purified mitochondrial Voltage-Dependent Anion Channel by c-Jun N-terminal Kinase-3 modifies channel voltage-dependence. Biochim. Open 4, 78-87. doi: 10.1016/j.biopen. 2017.03.002

Harper, J. F. (2001). Dissecting calcium oscillators in plant cells. Trends Plant Sci. 6, 395-397. doi: 10.1016/s1360-1385(01)02023-4

Heinss, L., Mentzels, H., Schmido, A., Benzo, R., and Schmitzsn, U. K. (1994). Biochemical, molecular, and functional characterization of porin isoforms from potato mitochondria*. J. Biol. Chem. 269, 26402-26410. doi: 10.1016/s00219258(18)47208-0

Hershko, A., Heller, H., Eytan, E., Kaklij, G., and Rose, I. A. (1984). Role of the $\alpha-$ amino group of protein in ubiquitin-mediated protein breakdown. Proc. Natl. Acad. Sci. U.S.A. 81, 7021-7025. doi: 10.1073/pnas.81.22.7021

Hiller, S., Garces, R. G., Malia, T. J., Orekhov, V. Y., Colombini, M., and Wagner, G. (2008). Solution structure of the integral human membrane protein VDAC1 in detergent micelles. Science 321, 1206-1210. doi: 10.1126/science.116 1302

Himschoot, E., Pleskot, R., Van Damme, D., and Vanneste, S. (2017). The ins and outs of $\mathrm{Ca} 2+$ in plant endomembrane trafficking. Curr. Opin. Plant Biol. 40, 131-137. doi: 10.1016/j.pbi.2017.09.003

Hodge, T., and Colombini, M. (1997). Regulation of metabolite flux through voltage-gating of vdac channels. J. Membr. Biol. 157, 271-279. doi: 10.1007/ s002329900235

Huang, H., Shah, K., Bradbury, N. A., Li, C., and White, C. (2014). Mcl-1 promotes lung cancer cell migration by directly interacting with VDAC to increase mitochondrial Ca2+uptake and reactive oxygen species generation. Cell Death Dis. 5:e1482. doi: 10.1038/cddis.2014.419

Imada, S., Yamamoto, M., Tanaka, K., Seiwa, C., Watanabe, K., Kamei, Y., et al. (2010). Hypothermia-induced increase of oligodendrocyte precursor cells: Possible involvement of plasmalemmal voltage-dependent anion channel 1 . J. Neurosci. Res. 88, 3457-3466. doi: 10.1002/jnr.22520

Jean-Quartier, C., Bondarenko, A. I., Alam, M. R., Trenker, M., WaldeckWeiermair, M., Malli, R., et al. (2012). Studying mitochondrial Ca $2+$ uptake - a revisit. Mol. Cell. Endocrinol. 353, 114-127. doi: 10.1016/j.mce. 2011.10.033

Ji, H., Pardo, J. M., Batelli, G., Van Oosten, M. J., Bressan, R. A., and Li, X. (2013). The salt overly sensitive (SOS) pathway: established and emerging roles. Mol. Plant 6, 275-286. doi: 10.1093/mp/sst017

Johnsen, V. L., Belke, D. D., Hughey, C. C., Hittel, D. S., Hepple, R. T., Koch, L. G., et al. (2013). Enhanced cardiac protein glycosylation (O-GlcNAc) of selected mitochondrial proteins in rats artificially selected for low running capacity. Physiol. Genomics 45, 17-25. doi: 10.1152/physiolgenomics.00111.2012

Jou, M. J. (2008). Pathophysiological and pharmacological implications of mitochondria-targeted reactive oxygen species generation in astrocytes. $A d v$. Drug Deliv. Rev. 60, 1512-1526. doi: 10.1016/j.addr.2008.06.004

Kim, M., Lim, J. H., Ahn, C. S., Park, K., Kim, G. T., Kim, W. T., et al. (2006). Mitochondria-associated hexokinases play a role in the control of programmed cell death in Nicotiana benthamiana. Plant Cell 18, 2341-2355. doi: 10.1105/ tpc.106.041509
Kmiecik, P., Leonardelli, M., and Teige, M. (2016). Novel connections in plant organellar signalling link different stress responses and signalling pathways. J. Exp. Bot. 67, 3793-3807. doi: 10.1093/jxb/erw136

Kudla, J., Becker, D., Grill, E., Hedrich, R., Hippler, M., Kummer, U., et al. (2018). Advances and current challenges in calcium signaling. New Phytol. 218, 414-431. doi: 10.1111/nph.14966

Le Mellay, V., Troppmair, J., Benz, R., and Rapp, U. R. (2002). Negative regulation of mitochondrial VDAC channels by C-Raf kinase. BMC Cell Biol. 3:14. doi: 10.1186/1471-2121-3-14

Lee, J., Xu, Y., Chen, Y., Sprung, R., Kim, S. C., Xie, S., et al. (2007). Mitochondrial phosphoproteome revealed by an improved IMAC method and MS/MS/MS. Mol. Cell. Proteomics 6, 669-676. doi: 10.1074/mcp.m600218-mcp200

Lee, S. M., Hoang, M. H. T., Han, H. J., Kim, H. S., Lee, K., Kim, K. E., et al. (2009). Pathogen inducible voltage-dependent anion channel (AtVDAC) isoforms are localized to mitochondria membrane in Arabidopsis. Mol. Cells 27, 321-327. doi: 10.1007/s10059-009-0041-Z

Li, Z.-Y., Xu, Z.-S., He, G.-Y., Yang, G.-X., Chen, M., Li, L.-C., et al. (2013). The voltage-dependent anion channel 1 (AtVDAC1) negatively regulates plant cold responses during germination and seedling development in Arabidopsis and interacts with calcium sensor CBL1. Int. J. Mol. Sci. 14, 701-713. doi: 10.3390/ijms14010701

Liberatori, S., Canas, B., Tani, C., Bini, L., Buonocore, G., Godovac-Zimmermann, J., et al. (2004). Proteomic approach to the identification of voltage-dependent anion channel protein isoforms in guinea pig brain synaptosomes. Proteomics 4, 1335-1340. doi: 10.1002/pmic.200300734

Liu, L., and Li, J. (2019). Communications between the endoplasmic reticulum and other organelles during abiotic stress response in plants. Front. Plant Sci. 10:749. doi: 10.3389/fpls.2019.00749

Liu, Z., Luo, Q. H., Wen, G. Q., Wang, J. M., Li, X. F., and Yang, Y. (2015). VDAC2 involvement in the stress response pathway in Arabidopsis thaliana. Genet. Mol. Res. 14, 15511-15519. doi: 10.4238/2015.december.1.1

Lodish, H. F. (1981). Post-translational modification of proteins. Enzyme Microb. Technol. 3, 178-188.

Logan, D. C., and Knight, M. R. (2003). Mitochondrial and cytosolic calcium dynamics are differentially regulated in plants. Plant Physiol. 133, 21-24. doi: 10.1104/pp.103.026047

Ludwig, O., Krause, J., Hay, R., and Benz, R. (1988). Purification and characterization of the pore forming protein of yeast mitochondrial outer membrane. Eur. Biophys. J. 15, 269-276. doi: 10.1007/bf00256477

Ma, H., Xiang, G., Li, Z., Wang, Y., Dou, M., Su, L., et al. (2018). Grapevine VpPR10.1 functions in resistance to Plasmopara viticola through triggering a cell death-like defence response by interacting with VpVDAC3. Plant Biotechnol. J. 16, 1488-1501. doi: 10.1111/pbi.12891

Maeda, K., and Ohsato, S. (2017). Molecular genetic characterization of \&1t;i\&gt; Fusarium graminearum \&1t;/i\&gt; genes identified as encoding a precocene II-binding protein. Mycotoxins 67, 1-3.

Malik, C., and Ghosh, S. (2020). Modulation of the mitochondrial voltagedependent anion channel (VDAC) by hydrogen peroxide and its recovery by curcumin. Eur. Biophys. J. 49, 661-672. doi: 10.1007/s00249-020-01469-2

Manning, L. R., and Manning, J. M. (2001). The acetylation state of human fetal hemoglobin modulates the strength of its subunit: long-range effects and implications for histone interactions in the nucleosome. Biochemistry 40, 1635-1639. doi: 10.1021/bi002157+

Martel, C., Allouche, M., Esposti, D. D., Fanelli, E., Boursier, C., Henry, C., et al. (2013). Glycogen synthase kinase 3-mediated voltage-dependent anion channel phosphorylation controls outer mitochondrial membrane permeability during lipid accumulation. Hepatology 57, 93-102. doi: 10.1002/hep.25967

Martel, C., Wang, Z., and Brenner, C. (2014). VDAC phosphorylation, a lipid sensor influencing the cell fate. Mitochondrion 19, 69-77. doi: 10.1016/j.mito. 2014.07.009

McKenzie, M., Lim, S. C., and Duchen, M. R. (2017). Simultaneous measurement of mitochondrial calcium and mitochondrial membrane potential in live cells by fluorescent microscopy. J. Vis. Exp. 119:55166.

Menzel, V. A., Cassará, M. C., Benz, R., De Pinto, V., Messina, A., Cunsolo, V., et al. (2009). Molecular and functional characterization of VDAC2 purified from mammal spermatozoa. Biosci. Rep. 29, 351-362. doi: 10.1042/bsr20080123

Munton, R. P., Tweedie-Cullen, R., Livingstone-Zatchej, M., Weinandy, F., Waidelich, M., Longo, D., et al. (2007). Qualitative and quantitative analyses 
of protein phosphorylation in naive and stimulated mouse synaptosomal preparations. Mol. Cell. Proteomics 6, 283-293. doi: 10.1074/mcp.m600046mcp200

Nangaku, M., Sato-Yoshitake, R., Okada, Y., Noda, Y., Takemura, R., Yamazaki, H., et al. (1994). KIF1B, a novel microtubule plus end-directed monomeric motor protein for transport of mitochondria. Cell 79, 1209-1220. doi: 10.1016/00928674(94)90012-4

Navazio, L., Formentin, E., Cendron, L., and Szabò, I. (2020). Chloroplast calcium signaling in the spotlight. Front. Plant Sci. 11:186. doi: 10.3389/fpls.2020.00186

Neuzillet, C., Tijeras-Raballand, A., Bourget, P., Cros, J., Couvelard, A., Sauvanet, A., et al. (2015). State of the art and future directions of pancreatic ductal adenocarcinoma therapy. Pharmacol. Ther. 155, 80-104. doi: 10.1016/j. pharmthera.2015.08.006

Niedzwiecka, K., Tisi, R., Penna, S., Lichocka, M., Plochocka, D., and Kucharczyk, R. (2018). Two mutations in mitochondrial ATP6 gene of ATP synthase, related to human cancer, affect ROS, calcium homeostasis and mitochondrial permeability transition in yeast. Biochim. Biophys. Acta Mol. Cell Res. 1865, 117-131. doi: 10.1016/j.bbamcr.2017.10.003

Okazaki, M., Kurabayashi, K., Asanuma, M., Saito, Y., Dodo, K., and Sodeoka, M. (2015). VDAC3 gating is activated by suppression of disulfide-bond formation between the N-terminal region and the bottom of the pore. Biochim. Biophys. Acta Biomembr. 1848, 3188-3196. doi: 10.1016/j.bbamem.2015.09.017

Olivas-Aguirre, M., Torres-López, L., Pottosin, I., and Dobrovinskaya, O. (2020). Phenolic compounds cannabidiol, curcumin and quercetin cause mitochondrial dysfunction and suppress acute lymphoblastic leukemia cells. Int. J. Mol. Sci. 22:204. doi: 10.3390/ijms22010204

Olivas-Aguirre, M., Torres-López, L., Valle-Reyes, J. S., Hernández-Cruz, A., Pottosin, I., and Dobrovinskaya, O. (2019). Cannabidiol directly targets mitochondria and disturbs calcium homeostasis in acute Lymphoblastic leukemia. Cell Death Dis. 10, 1-19.

Olsen, J. V., Blagoev, B., Gnad, F., Macek, B., Kumar, C., Mortensen, P., et al. (2006). Global, in vivo, and site-specific phosphorylation dynamics in signaling networks. Cell 127, 635-648. doi: 10.1016/j.cell.2006.09.026

Ott, M., Gogvadze, V., Orrenius, S., and Zhivotovsky, B. (2007). Mitochondria, oxidative stress and cell death. Apoptosis 12, 913-922. doi: 10.1007/s10495-0070756-2

Pandey, G. K. (2008). Emergence of a novel calcium signaling pathway in plants: CBL-CIPK signaling network. Physiol. Mol. Biol. Plants 14, 51-68. doi: 10.1007/ s12298-008-0005-3

Pastorino, J. G., and Hoek, J. B. (2008). Regulation of hexokinase binding to VDAC. J. Bioenerg. Biomembr. 40, 171-182. doi: 10.1007/s10863-008-9148-8

Pastorino, J. G., Hoek, J. B., and Shulga, N. (2005). Activation of glycogen synthase kinase $3 \beta$ disrupts the binding of hexokinase II to mitochondria by phosphorylating voltage-dependent anion channel and potentiates chemotherapy-induced cytotoxicity. Cancer Res. 65, 10545-10554. doi: 10.1158/0008-5472.can-05-1925

Pastorino, J. G., Shulga, N., and Hoek, J. B. (2002). Mitochondrial binding of hexokinase II inhibits Bax-induced cytochrome c release and apoptosis. J. Biol. Chem. 277, 7610-7618. doi: 10.1074/jbc.m109950200

Patel, S., and Muallem, S. (2011). Acidic Ca2+ stores come to the fore. Cell Calcium 50, 109-112. doi: 10.1016/j.ceca.2011.03.009

Peng, T. I., and Jou, M. J. (2010). "Oxidative stress caused by mitochondrial calcium overload," in Mitochondrial Research in Translational Medicine. Annals of the New York Academy of Sciences, 1st Edn, eds Y. H. Wei, C. H. Tzeng, and H. M. Lee (Malden, MA: Blackwell Publishing Inc.), 183-188.

Pereira, A. J., Dalby, B., Stewart, R. J., Doxsey, S. J., and Goldstein, L. S. B. (1997). Mitochondrial association of a plus end-directed microtubule motor expressed during mitosis in Drosophila. J. Cell Biol. 136, 1081-1090. doi: 10.1083/jcb.136. 5.1081

Perrier, J., Durand, A., Giardina, T., and Puigserver, A. (2005). Catabolism of intracellular N-terminal acetylated proteins: involvement of acylpeptide hydrolase and acylase. Biochimie 87, 673-685. doi: 10.1016/j.biochi.2005.04.002

Pesaresi, P., Gardner, N. A., Masiero, S., Dietzmann, A., Eichacker, L., Wickner, R., et al. (2003). Cytoplasmic N-terminal protein acetylation is required for efficient photosynthesis in Arabidopsis. Plant Cell 15, 1817-1832. doi: 10.1105/ tpc. 012377

Pittalà, M. G. G., Saletti, R., Reina, S., Cunsolo, V., De Pinto, V., and Foti, S. (2020). A high resolution mass spectrometry study reveals the potential of disulfide formation in human mitochondrial voltage-dependent anion selective channel isoforms (HVDACs). Int. J. Mol. Sci. 21:1468. doi: 10.3390/ijms21041468

Platanias, L. C. (2005). Mechanisms of type-I- and type-II-interferon-mediated signalling. Nat. Rev. Immunol. 5, 375-386. doi: 10.1038/nril604

Polevoda, B., Norbeck, J., Takakura, H., Blomberg, A., and Sherman, F. (1999). Identification and specificities of $\mathrm{N}$-terminal acetyltransferases from Saccharomyces cerevisiae. EMBO J. 18, 6155-6168. doi: 10.1093/emboj/18.21. 6155

Poovaiah, B. W., Reddy, A. S. N., and Leopold, C. (1987). Calcium messenger system in plants. Crit. Rev. Plant Sci. 1, 47-103. doi: 10.1080/ 07352688709382247

Pozzan, T., and Rudolf, R. (2009). Measurements of mitochondrial calcium in vivo. Biochim. Biophys. Acta Bioenerg. 1787, 1317-1323. doi: 10.1016/j.bbabio.2008. 11.012

Queralt-Martín, M., Bergdoll, L., Teijido, O., Munshi, N., Jacobs, D., Kuszak, A. J., et al. (2020). A lower affinity to cytosolic proteins reveals VDAC3 isoform-specific role in mitochondrial biology. J. Gen. Physiol 152, e201912501.

Rapizzi, E., Pinton, P., Szabadkai, G., Wieckowski, M. R., Vandecasteele, G., Baird, G., et al. (2002). Recombinant expression of the voltage-dependent anion channel enhances the transfer of $\mathrm{Ca} 2+$ microdomains to mitochondria. J. Cell Biol. 159, 613-624. doi: 10.1083/jcb.200205091

Raschle, T., Hiller, S., Yu, T. Y., Rice, A. J., Walz, T., and Wagner, G. (2009). Structural and functional characterization of the integral membrane protein VDAC-1 in lipid bilayer nanodiscs. J. Am. Chem. Soc. 131, 17777-17779. doi: 10.1021/ja907918r

Reina, S., Checchetto, V., Saletti, R., Gupta, A., Chaturvedi, D., Guardiani, C., et al. (2016). VDAC3 as a sensor of oxidative state of the intermembrane space of mitochondria: the putative role of cysteine residue modifications. Oncotarget 7 , 2249-2268. doi: 10.18632/oncotarget.6850

Reina, S., Pittalà, M. G. G., Guarino, F., Messina, A., De Pinto, V., Foti, S., et al. (2020). Cysteine oxidations in mitochondrial membrane proteins: the case of VDAC isoforms in mammals. Front. Cell Dev. Biol. 8:397. doi: 10.3389/fcell. 2020.00397

Rimmerman, N., Ben-Hail, D., Porat, Z., Juknat, A., Kozela, E., Daniels, M. P., et al. (2013). Direct modulation of the outer mitochondrial membrane channel, voltage-dependent anion channel 1 (VDAC1) by cannabidiol: a novel mechanism for cannabinoid-induced cell death. Cell Death Dis. 4:e949. doi: 10.1038/cddis.2013.471

Rizzuto, R., De Stefani, D., Raffaello, A., and Mammucari, C. (2012). Mitochondria as sensors and regulators of calcium signalling. Nat. Rev. Mol. Cell Biol. 13, 566-578. doi: $10.1038 / \mathrm{nrm} 3412$

Rossi, C. S., and Lehninger, A. L. (1963). Stoichiometric relationships between mitochondrial ion accumulation and oxidative phosphorylation. Biochem. Biophys. Res. Commun. 11, 441-446. doi: 10.1016/0006-291x(63)90089-5

Rostovtseva, T. K., Sheldon, K. L., Hassanzadeh, E., Monge, C., Saks, V., Bezrukov, S. M., et al. (2008). Tubulin binding blocks mitochondrial voltage-dependent anion channel and regulates respiration. Proc. Natl. Acad. Sci. U.S.A. 105, 18746-18751. doi: 10.1073/pnas.0806303105

Rudd, J. J., and Franklin-Tong, V. E. (1999). Calcium signaling in plants. Cell. Mol. Life Sci. 55, 214-232.

Rudd, J. J., and Franklin-Tong, V. E. (2001). Unravelling response-specificity in $\mathrm{Ca}^{2+}$ signalling pathways in plant cells. New Phytol. 151, 7-33. doi: 10.1046/j. 1469-8137.2001.00173.x

Ryan, B. J., Nissim, A., and Winyard, P. G. (2014). Oxidative post-translational modifications and their involvement in the pathogenesis of autoimmune diseases. Redox Biol. 2, 715-724. doi: 10.1016/j.redox.2014.05.004

Saidani, H., Grobys, D., Léonetti, M., Kmita, H., and Homblé, F. (2016). Towards understanding of plant mitochondrial VDAC proteins: an overview of bean (Phaseolus) VDAC proteins. AIMS Biophys. 4, 43-62. doi: 10.3934/biophy. 2017.1.43

Saletti, R., Reina, S., Pittalà, M. G. G., Belfiore, R., Cunsolo, V., Messina, A., et al. (2017). High resolution mass spectrometry characterization of the oxidation pattern of methionine and cysteine residues in rat liver mitochondria voltage-dependent anion selective channel 3 (VDAC3). Biochim. Biophys. Acta Biomembr. 1859, 301-311. doi: 10.1016/j.bbamem.2016.12. 003

Saletti, R., Reina, S., Pittalà, M. G. G., Magrì, A., Cunsolo, V., Foti, S., et al. (2018). Post-translational modifications of VDAC1 and VDAC2 cysteines from 
rat liver mitochondria. Biochim. Biophys. Acta Bioenerg. 1859, 806-816. doi: 10.1016/j.bbabio.2018.06.007

Sanders, D., Brownlee, C., and Harper, J. F. (1999). Communicating with calcium. Plant Cell 11, 691-706. doi: 10.2307/3870893

Sanyal, S. K., Mahiwal, S., Nambiar, D. M., and Pandey, G. K. (2020). CBL-CIPK module-mediated phosphoregulation: facts and hypothesis. Biochem. J. 477, 853-871. doi: 10.1042/bcj20190339

Sanyal, S. K., Pandey, A., and Pandey, G. K. (2015). The CBL-CIPK signaling module in plants: a mechanistic perspective. Physiol. Plant. 155, 89-108. doi: $10.1111 / \mathrm{ppl} .12344$

Sanyal, S. K., Rao, S., Mishra, L. K., Sharma, M., and Pandey, G. K. (2016). Plant stress responses mediated by CBL-CIPK phosphorylation network. Enzymes 40, 31-64. doi: 10.1016/bs.enz.2016.08.002

Schein, S. J., Colombini, M., and Finkelstein, A. (1976). Reconstitution in planar lipid bilayers of a voltage-dependent anion-selective channel obtained from paramecium mitochondria. J. Membr. Biol. 30, 99-120. doi: 10.1007/ bf01869662

Schwertz, H., Carter, J. M., Abdudureheman, M., Russ, M., Buerke, U., Schlitt, A., et al. (2007). Myocardial ischemia/reperfusion causes VDAC phosphorylation which is reduced by cardioprotection with a p38 MAP kinase inhibitor. Proteomics 7, 4579-4588. doi: 10.1002/pmic.200700734

Sena, L. A., and Chandel, N. S. (2012). Physiological roles of mitochondrial reactive oxygen species. Mol. Cell 48, 158-167. doi: 10.1016/j.molcel.2012.09.025

Shakir, S., Vinh, J., and Chiappetta, G. (2017). Quantitative analysis of the cysteine redoxome by iodoacetyl tandem mass tags. Anal. Bioanal. Chem. 409, $3821-$ 3830. doi: 10.1007/s00216-017-0326-6

Sheldon, K. L., Maldonado, E. N., Lemasters, J. J., Rostovtseva, T. K., and Bezrukov, S. M. (2011). Phosphorylation of voltage-dependent anion channel by serine/threonine kinases governs its interaction with tubulin. PLoS One 6:25539. doi: 10.1371/journal.pone.0025539

Singh, V., Khalil, M. I., and De Benedetti, A. (2020). The TLK1/Nek1 axis contributes to mitochondrial integrity and apoptosis prevention via phosphorylation of VDAC1. Cell Cycle 19, 363-375. doi: 10.1080/15384101. 2019.1711317

Smaili, S., Hirata, H., Ureshino, R., Monteforte, P. T., Morales, A. P., Muler, M. L., et al. (2009). Calcium and cell death signaling in neurodegeneration and aging. An. Acad. Bras. Cienc. 81, 467-475. doi: 10.1590/s0001-37652009000300011

Stael, S., Wurzinger, B., Mair, A., Mehlmer, N., Vothknecht, U. C., and Teige, M. (2012). Plant organellar calcium signalling: an emerging field. J. Exp. Bot. 63 1525-1542. doi: 10.1093/jxb/err394

Stipanuk, M. H., Ueki, I., Dominy, J. E., Simmons, C. R., and Hirschberger, L. L. (2009). Cysteine dioxygenase: A robust system for regulation of cellular cysteine levels. Amino Acids 37, 55-63.

Sullivan, L. B., and Chandel, N. S. (2014). Mitochondrial reactive oxygen species and cancer. Cancer Metab. 2:17.

Sunavala-Dossabhoy, G., and De Benedetti, A. (2009). Tousled homolog, TLK1, binds and phosphorylates Rad9; TLK1 acts as a molecular chaperone in DNA repair. DNA Repair (Amst) 8, 87-102. doi: 10.1016/j.dnarep.2008.09.005

Szabadkai, G., Bianchi, K., Várnai, P., De Stefani, D., Wieckowski, M. R., Cavagna, D., et al. (2006). Chaperone-mediated coupling of endoplasmic reticulum and mitochondrial Ca2+ channels. J. Cell Biol. 175, 901-911. doi: 10.1083/jcb. 200608073

Tanaka, Y., Kanai, Y., Okada, Y., Nonaka, S., Takeda, S., Harada, A., et al. (1998). Targeted disruption of mouse conventional kinesin heavy chain, kif5B, results in abnormal perinuclear clustering of mitochondria. Cell 93, 1147-1158. doi: 10.1016/s0092-8674(00)81459-2

Tang, R. J., Wang, C., Li, K., and Luan, S. (2020). The CBL-CIPK calcium signaling network: unified paradigm from 20 years of discoveries. Trends Plant Sci. 25, 604-617. doi: 10.1016/j.tplants.2020.01.009

Tateda, C., Watanabe, K., Kusano, T., and Takahashi, Y. (2011). Molecular and genetic characterization of the gene family encoding the voltage-dependent anion channel in Arabidopsis. J. Exp. Bot. 62, 4773-4785. doi: 10.1093/jxb/ err113

Tateda, C., Yamashita, K., Takahashi, F., Kusano, T., and Takahashi, Y. (2009). Plant voltage-dependent anion channels are involved in host defense against Pseudomonas cichorii and in Bax-induced cell death. Plant Cell Rep. 28, 41-51. doi: 10.1007/s00299-008-0630-x
Teijido, O., Ujwal, R., Hillerdal, C. O., Kullman, L., Rostovtseva, T. K., and Abramson, J. (2012). Affixing N-terminal $\alpha$-helix to the wall of the voltagedependent anion channel does not prevent its voltage gating. J. Biol. Chem. 287, 11437-11445. doi: 10.1074/jbc.m111.314229

Tewari, D., Ahmed, T., Chirasani, V. R., Singh, P. K., Maji, S. K., Senapati, S., et al. (2015). Modulation of the mitochondrial voltage dependent anion channel (VDAC) by curcumin. Biochim. Biophys. Acta Biomembr. 1848, 151-158. doi: 10.1016/j.bbamem.2014.10.014

Tewari, D., Mukhopadhyay, M., Nekkanti, M. S., Vallabhaneni, S., Sahu, G., Jetti, S. K., et al. (2016). Cytoprotective effect of Centella asiatica is mediated through the modulation of mitochondrial voltage-dependent anion channel (VDAC) and scavenging of free radicals. J. Funct. Foods 21, 301-311. doi: 10.1016/j.jff. 2015.11.047

Tewari, S. G., Zhou, Y., Otto, B. J., Dash, R. K., Kwok, W.-M., and Beard, D. A. (2015). Markov chain Monte Carlo based analysis of post-translationally modified VDAC gating kinetics. Front. Physiol. 5:513. doi: 10.3389/fphys.2014. 00513

Tikunov, A., Johnson, C. B., Pediaditakis, P., Markevich, N., Macdonald, J. M., Lemasters, J. J., et al. (2010). Closure of VDAC causes oxidative stress and accelerates the $\mathrm{Ca} 2+$-induced mitochondrial permeability transition in rat liver mitochondria. Arch. Biochem. Biophys. 495, 174-181. doi: 10.1016/j.abb.2010. 01.008

Geiger, T. R., Keith, C. S., Muszynski, M. G., and Newton, K. J. (1999). Sequences of three maize cdnas encoding mitochondrial voltage-dependent anion channel (VDAC) proteins (Accession Nos. AF178950, AF178951, AF178952). (PGR99156). Plant Physiol. 121, 686-686.

Trewavas, A. (1999). Le calcium, c'est la vie: calcium makes waves. Plant Physiol. 120, 1-6. doi: 10.1104/pp.120.1.1

Ujwal, R., Cascio, D., Colletier, J. P., Faham, S., Zhang, J., Toro, L., et al. (2008). The crystal structure of mouse VDAC1 at $2.3 \AA$ resolution reveals mechanistic insights into metabolite gating. Proc. Natl. Acad. Sci. U.S.A. 105, 17742-17747. doi: 10.1073/pnas.0809634105

Wagner, S., De Bortoli, S., Schwarzländer, M., and Szabò, I. (2016). Regulation of mitochondrial calcium in plants versus animals. J. Exp. Bot. 67, 3809-3829. doi: 10.1093/jxb/erw100

Wandrey, M., Trevaskis, B., Brewin, N., and Udvardi, M. K. (2004). Molecular and cell biology of a family of voltage-dependent anion channel porins in Lotus japonicus. Plant Physiol. 134, 182-193. doi: 10.1104/pp.103.031484

Wang, C., Xu, H., Lin, S., Deng, W., Zhou, J., Zhang, Y., et al. (2020). GPS 5.0: an update on the prediction of kinase-specific phosphorylation sites in proteins. Genomics Proteomics Bioinformatics 18, 72-80. doi: 10.1016/j.gpb.2020.01.001

Wang, H. G., Miyashita, T., Takayama, S., Sato, T., Torigoe, T., Krajewski, S., et al. (1994). Apoptosis regulation by interaction of $\mathrm{Bcl}-2$ protein and Raf-1 kinase. Oncogene 9, 2751-2756.

Wang, H. G., Rapp, U. R., and Reed, J. C. (1996). Bcl-2 targets the protein kinase Raf-1 to mitochondria. Cell 87, 629-638. doi: 10.1016/s0092-8674(00)81383-5

Wang, Z., Qin, J., Zhao, J., Li, J., Li, D., Popp, M., et al. (2020). Inflammatory IFIT3 renders chemotherapy resistance by regulating post-translational modification of VDAC2 in pancreatic cancer. Theranostics 10, 7178-7192. doi: 10.7150/thno. 43093

Wen, G., Cai, L., Liu, Z., Li, D., Luo, Q., Li, X., et al. (2011). Arabidopsis thaliana VDAC2 involvement in salt stress response pathway. Afr. J. Biotechnol. 10, 11588-11593.

Wen, G., Yang, Y., Chai, L., Liu, Z., and Wang, J. (2014). Overexpression of the voltage-dependent anion channel 2 (VDAC2) gene induces drought resistance in Arabidopsis thaliana. Plant Omics 7, 171-177.

Yaguchi, A., Yoshinari, T., Tsuyuki, R., Takahashi, H., Nakajima, T., Sugita-Konishi, Y., et al. (2009). Isolation and identification of precocenes and piperitone from essential oils as specific inhibitors of trichothecene production by Fusarium graminearum. J. Agric. Food Chem. 57, 846-851. doi: 10.1021/jf802813h

Yan, Y., Wei, C., Zhang, W., Cheng, H., and Liu, J. (2006). Cross-talk between calcium and reactive oxygen species signaling. Acta Pharmacol. Sin. 27, 821826. doi: 10.1111/j.1745-7254.2006.00390.x

Yang, X. Y., Chen, Z. W., Xu, T., Qu, Z., Di Pan, X., Qin, X. H., et al. (2011). Arabidopsis kinesin KP1 specifically interacts with VDAC3, a mitochondrial protein, and regulates respiration during seed germination at low temperature. Plant Cell 23, 1090-1106. 
Yao, G.-Y., Zhu, Q., Xia, J., Chen, F.-J., Huang, M., Liu, J., et al. (2018). Ischemic postconditioning confers cerebroprotection by stabilizing VDACs after brain ischemia. Cell Death Dis. 9:1033.

Young, M. J., Bay, D. C., Hausner, G., and Court, D. A. (2007). The evolutionary history of mitochondrial porins. BMC Evol. Biol. 7:31. doi: 10.1186/1471-21487-31

Yuan, S., Fu, Y., Wang, X., Shi, H., Huang, Y., Song, X., et al. (2008). Voltagedependent anion channel 1 is involved in endostatin-induced endothelial cell apoptosis. FASEB J. 22, 2809-2820. doi: 10.1096/fj.08-107417

Zemirli, N., Morel, E., and Molino, D. (2018). Mitochondrial dynamics in basal and stressful conditions. Int. J. Mol. Sci. 19:564. doi: 10.3390/ijms19020564

Zhang, M., Liu, S., Takano, T., and Zhang, X. (2019). The interaction between AtMT2b and AtVDAC3 affects the mitochondrial membrane potential and reactive oxygen species generation under $\mathrm{NaCl}$ stress in Arabidopsis. Planta 249, 417-429. doi: 10.1007/s00425-018-3010-y

Zhang, M., Takano, T., Liu, S., and Zhang, X. (2015). Arabidopsis mitochondrial voltage-dependent anion channel 3 (AtVDAC3) protein interacts with thioredoxin m2. FEBS Lett. 589, 1207-1213. doi: 10.1016/j.febslet.2015.03.034

Zhao, S., Xiao, P., Cui, H., Gong, P., Lin, C., Chen, F., et al. (2020). Hypothermia-induced ubiquitination of voltage-dependent anion channel 3 protects bv2 microglia cells from cytotoxicity following oxygen-glucose deprivation/recovery. Front. Mol. Neurosci. 13:100. doi: 10.3389/fnmol.2020. 00100

Zhu, H., Jin, Q., Li, Y., Ma, Q., Wang, J., Li, D., et al. (2018). Melatonin protected cardiac microvascular endothelial cells against oxidative stress injury via suppression of IP3R-[Ca2+]c/VDAC-[Ca2+]m axis by activation of MAPK/ERK signaling pathway. Cell Stress Chaperones 23, 101-113. doi: 10. 1007/s12192-017-0827-4

Zörb, C., Schmitt, S., and Mühling, K. H. (2010). Proteomic changes in maize roots after short-term adjustment to saline growth conditions. Proteomics 10, 4441-4449. doi: 10.1002/pmic. 201000231

Conflict of Interest: The authors declare that the research was conducted in the absence of any commercial or financial relationships that could be construed as a potential conflict of interest.

Publisher's Note: All claims expressed in this article are solely those of the authors and do not necessarily represent those of their affiliated organizations, or those of the publisher, the editors and the reviewers. Any product that may be evaluated in this article, or claim that may be made by its manufacturer, is not guaranteed or endorsed by the publisher.

Copyright (c) 2021 Ravi, Kanwar, Sanyal, Bheri and Pandey. This is an open-access article distributed under the terms of the Creative Commons Attribution License (CC BY). The use, distribution or reproduction in other forums is permitted, provided the original author(s) and the copyright owner(s) are credited and that the original publication in this journal is cited, in accordance with accepted academic practice. No use, distribution or reproduction is permitted which does not comply with these terms. 